\title{
Heparanase: a rainbow pharmacological target associated to multiple pathologies including rare diseases
}

In recent years, heparanase has attracted considerable attention as a promising target for innovative pharmacological applications. Heparanase is a multifaceted protein endowed with enzymatic activity, as an endo- $\beta$-D-glucuronidase, and nonenzymatic functions. It is responsible for the cleavage of heparan sulfate side chains of proteoglycans, resulting in structural alterations of the extracellular matrix. Heparanase appears to be involved in major human diseases, from the most studied tumors to chronic inflammation, diabetic nephropathy, bone osteolysis, thrombosis and atherosclerosis, in addition to more recent investigation in various rare diseases. The present review provides an overview on heparanase, its biological role, inhibitors and possible clinical applications, covering the latest findings in these areas.

First draft submitted: 16 January 2016; Accepted for publication: 17 February 2016; Published online: 8 April 2016

Keywords: angiogenesis $\bullet$ cancer and metastasis $\bullet$ endo- $\beta$-D-glucuronidase $\bullet$ heparanase - heparanase structure $\bullet$ heparanase inhibitors $\bullet$ heparanase in vitro assays $\bullet$ inflammation

- modified heparins $\bullet$ rare diseases

This review is focused on human heparanase 1 , hereinafter simply referred to as heparanase, as called for the first time in 1984 by M Nakajima et al. [1], although the concept 'heparanase' had been reported years before (Supplementary Tables $1 \& 2$ ). To quote the words of NJ Nasser and E Nevo, authors of a recent review on this enzyme, considered as a target with "dim past and bright future" [2], we consider heparanase as a new biological target with multiple therapeutic applications as well as other, at this time, unpredictable applications of public health, associated with a growing pharmaceutical interest.

Under normal physiological conditions, heparanase (Hpse) is an enzyme expressed at high levels in placenta and some bloodborne cells including platelets, neutrophils, mast cells and lymphocytes, and is undetectable in other human tissues, but researchers are unveiling its role increasingly important in different pathological conditions [3-5].
Heparanase is the only known mammalian endo- $\beta$-D-glucuronidase capable of cleaving glycosaminoglycan heparan sulfate (HS) side chains of heparan sulfate proteoglycans (HSPGs) in a distinct manner [4]. HSPGs are localized mainly in the basement membrane (BM) (e.g., perlecan, collagen), on cell surface (e.g., syndecans 1-4, glypicans 1-6) and in the extracellular matrix (ECM), and have also been identified in the nucleus of certain cells $[6,7]$.

Heparanase regulates the bioavailability and activity of several bioactive molecules interacting with HS in HSPGs. More in detail, HSPGs bind to ECM components such as laminin, collagen IV and fibronectin, participating in the structural integrity and insolubility of ECM and BM. Moreover, HS chains are also associated with growth factors, lipoproteins, chemokines and enzymes and their degradation into smaller fractions usually allows the release of these factors
Silvia Rivara', Ferdinando M Milazzo ${ }^{2}$ \& Giuseppe Giannini*,3 'Dipartimento di Farmacia, Università degli Studi di Parma, Parco Area delle Scienze 27/A. I-43124 Parma, Italy 2Biotechnology, R\&D Sigma-Tau IFR S.p.A., via Pontina, km 30,400. I-00071 Pomezia (RM), Italy ${ }^{3}$ Medicinal Chemistry, R\&D Sigma-Tau IFR S.p.A., via Pontina, km 30,400. I-00071 Pomezia (RM), Italy *Author for correspondence: giuseppe.giannini@sigma-tau.it 
and activation of their signaling processes in response to local environmental alterations. For these reasons, HSPGs function as a barrier to cell migration, and as a reservoir of HS-bound growth factors and cytokines (Figure 1) [8-11].

On the other hand, heparanase functions are not limited to HS cleavage or the release of HS-sequestered growth factors, but this enzyme also plays a homeostatic role in regulating the turnover of cell-associated HS, affects clustering, shedding and mitogenic activity of HSPGs, for example, cell surface syndecans, which are the main heparanase targets, and degrades and participates in the remodeling of the ECM.

Normally, for human heparanase we refer to the type 1 isoform (Hpse1); however, it is worthy to note that a second isoform is also reported, heparanase 2 (Hpse2), discovered in 2000 by the UK team headed by E McKenzie [12]. Hpse2, with a homology of about $40 \%$ with Hpsel, does not exhibit enzymatic activity and its role in normal physiology and pathological disorders remains unclear, although recent findings are breakthroughs in the field of Hpse2, stimulating a growing interest toward this isoform, both in oncology and in other contexts [13-15].

Just to complete the picture, we quote another class of endoglycosidases, from bacteria, called heparinases (heparin lyases). Heparinases selectively cleave the glycosidic bond between glucosamine residues and uronic acids via an elimination mechanism, creating a double bond at the nonreducing end of the uronic acid (Figure 2). Three heparinase enzymes have been identified (heparinase I, II and III) with different substrate specificity. Heparinase I cleaves highly sulfated heparin/HS chains [16], heparinase III cleaves less sul-

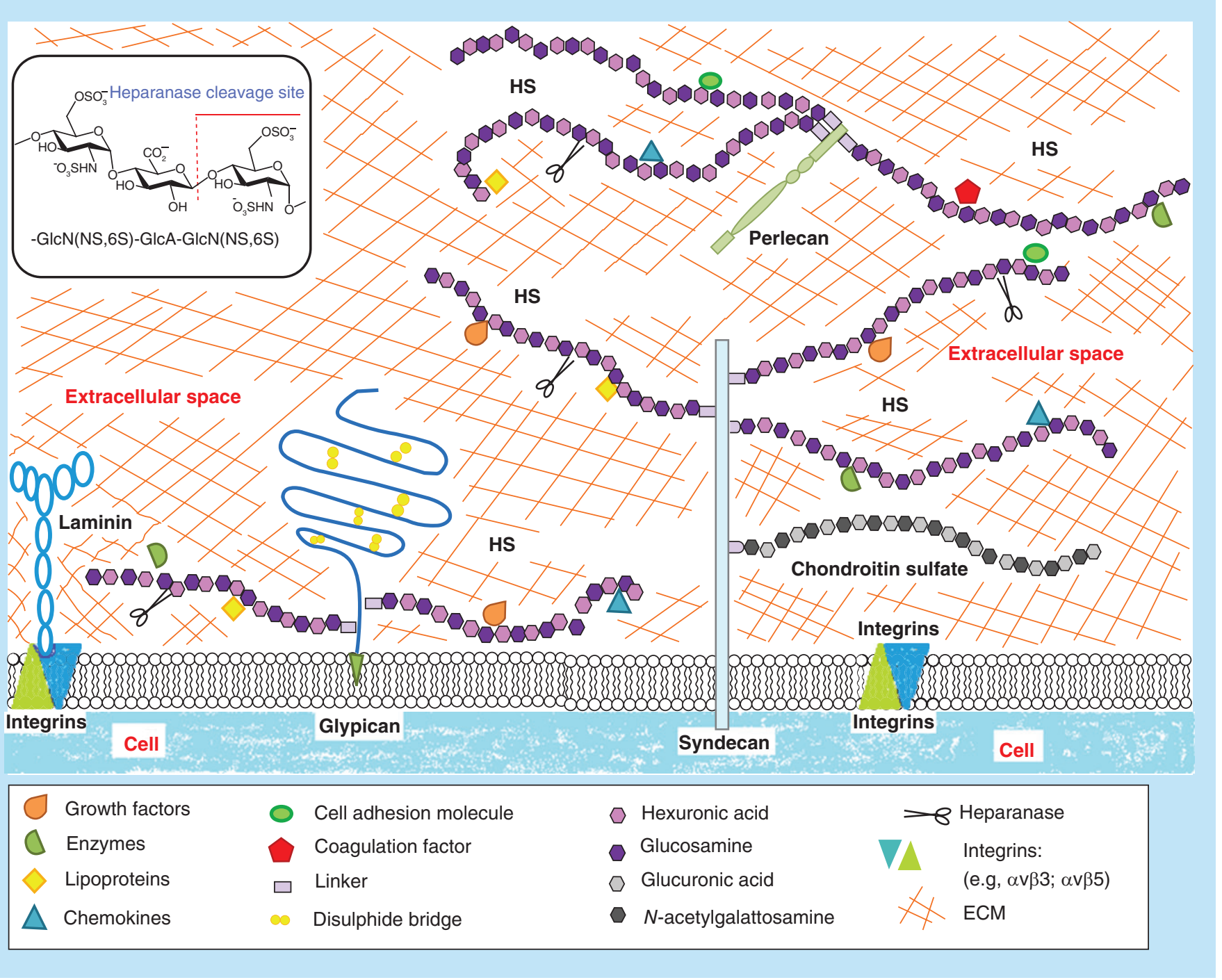

Figure 1. Extracellular space organization. Basement- and cellular membrane-associated heparan sulfate proteoglycans cleaved by heparanase. The box highlights heparanase cleavage site within the structure of heparan sulfate. ECM: Extracellular matrix; HS: Heparan sulfate. 
fated HS chains, while heparinase II cleaves domains of both high and low sulfation on heparin and HS [17]. Heparinase I, II and III used in combination can produce a near-complete depolymerization of heparin/HS polysaccharide chains to disaccharides.

\section{Heparanase expression \& activation, structure \& substrate specificity}

The primary structure of heparanase is highly conserved, with significant sequence similarity not only among mammals, but also with animals belonging to other classes, such as chickens and zebrafish. In humans, heparanase is encoded by a single copy HPSE gene, which is located on chromosome 4q21.3 and expressed as two (5 and $1.7 \mathrm{~kb}$ ) mRNA species by alternative splicing [19]. Toward the end of the 1990 's, there was a big breakthrough in the heparanase field: in 1999 five excellent teams of researchers published papers describing the cloning of the heparanase gene - Vlodavsky et al. [20]; Hulett et al. [21]; Kussie et al. [22]; Fairbanks et al. [23]; Toyoshima and Nakajima [24] - and three patents had already been filed by Vlodavsky (September 2, 1997; WO99011798), Parish (October 28, 1997; WO99021975) and Nakajima (8 February 1998; WO99040207). For the rules of priority, the patent was granted to the group that filed the patent first (Vlodavsky). Gene cloning represented a milestone in the research in this field [2].

Heparanase is first produced as a preproenzyme (preproheparanase) of 543 amino acids. The $\mathrm{N}$-terminal signal peptide (Met1-Ala35) is removed upon translocation into the endoplasmic reticulum, generating a latent $65 \mathrm{kDa}$ proenzyme (proheparanase), which is then shuttled to the Golgi apparatus where it is encapsulated into vesicles and, subsequently, secreted (Figure 3). Once secreted, proheparanase interacts with various extracellular components, comprising HS in HSPGs and mannose-6-phosphate receptors, and is then rapidly internalized by cellular uptake into latent endosomes and lysosomes, eventually leading to its activation [25]. Lysosomal activation of proheparanase generates the mature noncovalent heterodimer composed of the N-terminal $8 \mathrm{kDa}$ (Gln36-Glu109) and the C-terminal $50 \mathrm{kDa}$ (Lys158-Ile543) chains (Figure 4) [26]. Heparanase activation is achieved by excision of a $6 \mathrm{kDa}$ linker peptide (Ser110-Gln157) catalyzed by lysosomal cathepsins, with cathepsin L identified as the major intervening enzyme [27]. It was demonstrated that cathepsin L cleaves Gln157-Lys158 amide bond, but it is likely involved in the removal of the entire linker region [28]. The $8 \mathrm{kDa}$ peptide is required for catalytic activity, and cloning of the 50 $\mathrm{kDa}$ chain alone failed to produce a functional protein [29]. Typically, the active enzyme is localized in

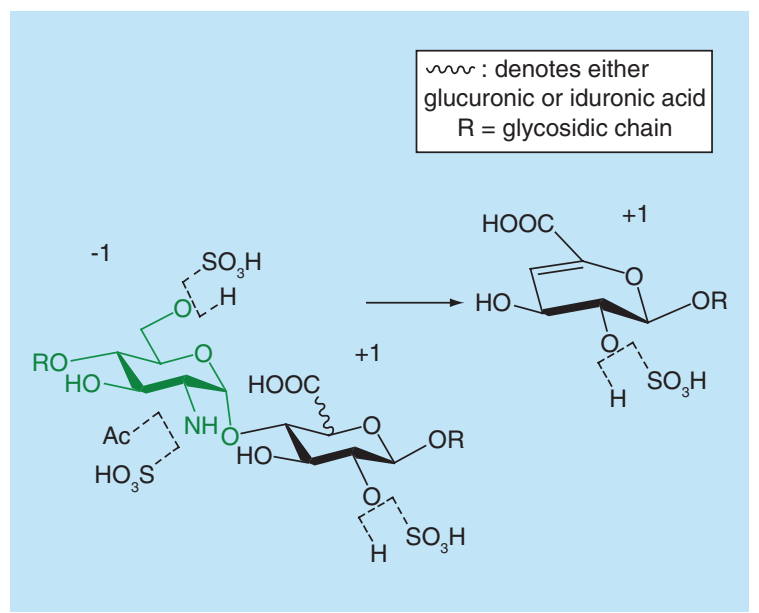

Figure 2. Cleavage of the glycosidic bond by

heparinase. Sugar sites are named according to the nomenclature by Davies et al. [18].

perinuclear acidic endosomal and lysosomal granules of fibroblasts and tumor cells and in the tertiary granules of human neutrophils, where it is co-localized with MMP-9 ([4] and references cited herein), ready to be released, under the control of internal and external cellular signals [30].

A tight regulation of heparanase expression, processing and activation has been recognized, not only based on regulation of gene transcription, but also on proheparanase secretion in response to different cellular stimuli and subsequent intracellular migration and lysosomal activation. Heparanase activity is further modulated by pathophysiological conditions, such as the $\mathrm{pH}$ of the microenvironment; it is essentially inactive at neutral $\mathrm{pH}$, but becomes active under acidic conditions, assuring an optimal enzymatic activity at $\mathrm{pH}$ values between 5 and 6 , such as during tumor invasion and in inflammatory processes.

Two alternatively spliced and catalytically inactive variants of heparanase were identified. The truncated, 169 amino acid-long, T5 splice variant is generated by fusion of exon 4 with 144 base pairs of intron 5 [33]. The other reported splice variant lacks exon 5 , missing 174 bp compared with the wild type cDNA. A 485 amino acid-long protein is synthesized, in which one of the catalytic amino acids (Glu225) is missing [34].

Multiple sequence alignment and folding prediction led to the classification of heparanase as a member of clan A glycosyl hydrolases. An $(\beta / \alpha)_{8}$-TIM barrel fold (eight alternating $\beta$-strands and $\alpha$-helices) was proposed as its $3 \mathrm{D}$ architecture, in which the first three secondary structure elements are provided by the 8 $\mathrm{kDa}$ chain and the others by the $50 \mathrm{kDa}$ one [35]. This folding has been recently confirmed by its crystal structure (Figure 4) [32]. Besides the TIM barrel domain, the $50 \mathrm{kDa}$ chain also folds into a carboxy-terminal 


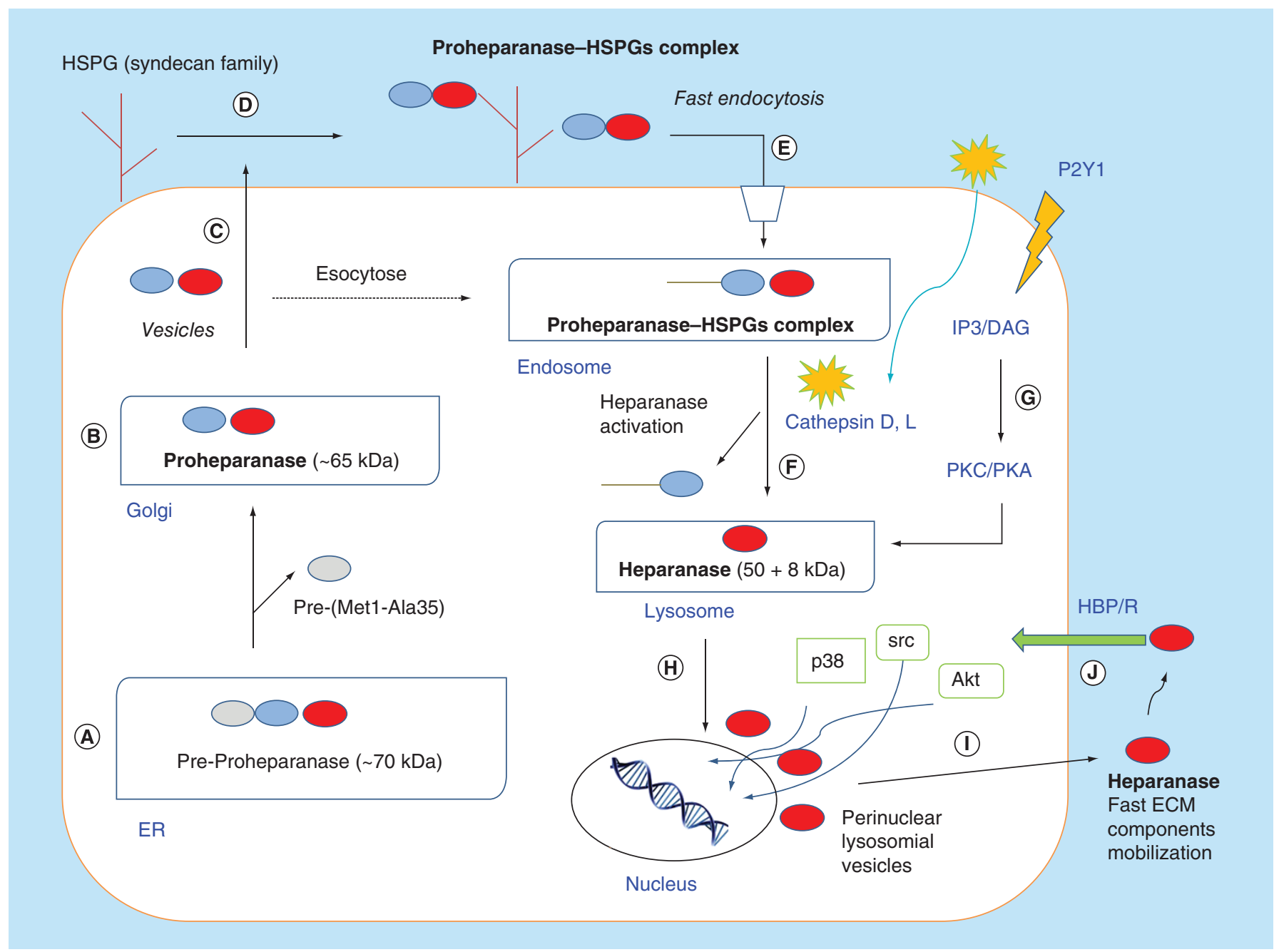

Figure 3. Heparanase biosynthesis and trafficking. (A) Biosynthesis of preproheparanase on the endoplasmic reticulum lumen; (B) Shuttling of the $65 \mathrm{kDa}$ proheparanase toward the Golgi apparatus; (C) Secretion via vesicles of proheparanase toward the extracellular compartment. (D) Fast interaction with cell membrane HSPGs (i.e., syndecan-family members); (E) Rapid endocytosis of the heparanase-HSPG complex and accumulation in endosomes; (F) Conversion of endosomes to lysosomes associated with heparanase activation by cathepsin family members, mainly cathepsin D and L [27]; (G) Heparanase secretion was stimulated with a specific P2Y1 receptor agonist and was inhibited by P2Y1 receptor antagonists. P2Y1 receptor activation is coupled to phospholipase $\mathrm{C}$ and adenylate cyclase activation, leading to PKC and PKA activation [30]; (H) Perinuclear lysosomal vesicles of heparanase; (I) Liberation of active heparanase in the extracellular compartment with a fast mobilization of ECM components, required for inflammation, proliferation and metastases; $(J)$ Heparanase binding cell surface protein/receptor: HS-independent Akt, p38 and Src activation resulting in enhanced transcription of genes such as VEGF [31].

ECM: Extracellular matrix; ER: Endoplasmic reticulum; HS: Heparan sulfate; HSPG: Heparan sulfate proteoglycans.

Data taken from [28].

$\beta$-sandwich domain (411-543) comprising $8 \beta$-strands, which is essential for protein secretion and enzymatic activity [36]. This terminal domain was also found to mediate nonenzymatic activities of heparanase. Sequence analysis predicted six potential N-linked glycosylation sites. Glycosylation regulates heparanase secretion, but it is not essential for enzymatic activity.

Heparanase is an endo- $\beta$-D-glucuronidase, catalyzing the hydrolysis of the $\beta$-glycosidic bond at specific intrachain sites with a retaining mechanism (with retention of the anomeric configuration) [37]. It uses a general acid catalysis mechanism, employing two essential acidic residues, which were identified by sitedirected mutagenesis as Glu225 and Glu343, acting as the proton donor and the nucleophile, respectively [38].

Sequence analysis of heparin-binding domains (HBDs) from different proteins led to the identification of three clusters of basic amino acids in the $50 \mathrm{kDa}$ chain of heparanase, two of which (HBD1:Lys158-Asp171; HBD-2:Gln270-Lys280) involved in the interaction with the negatively charged HS substrate [39]. HBD-1 is located at the N-terminal portion 


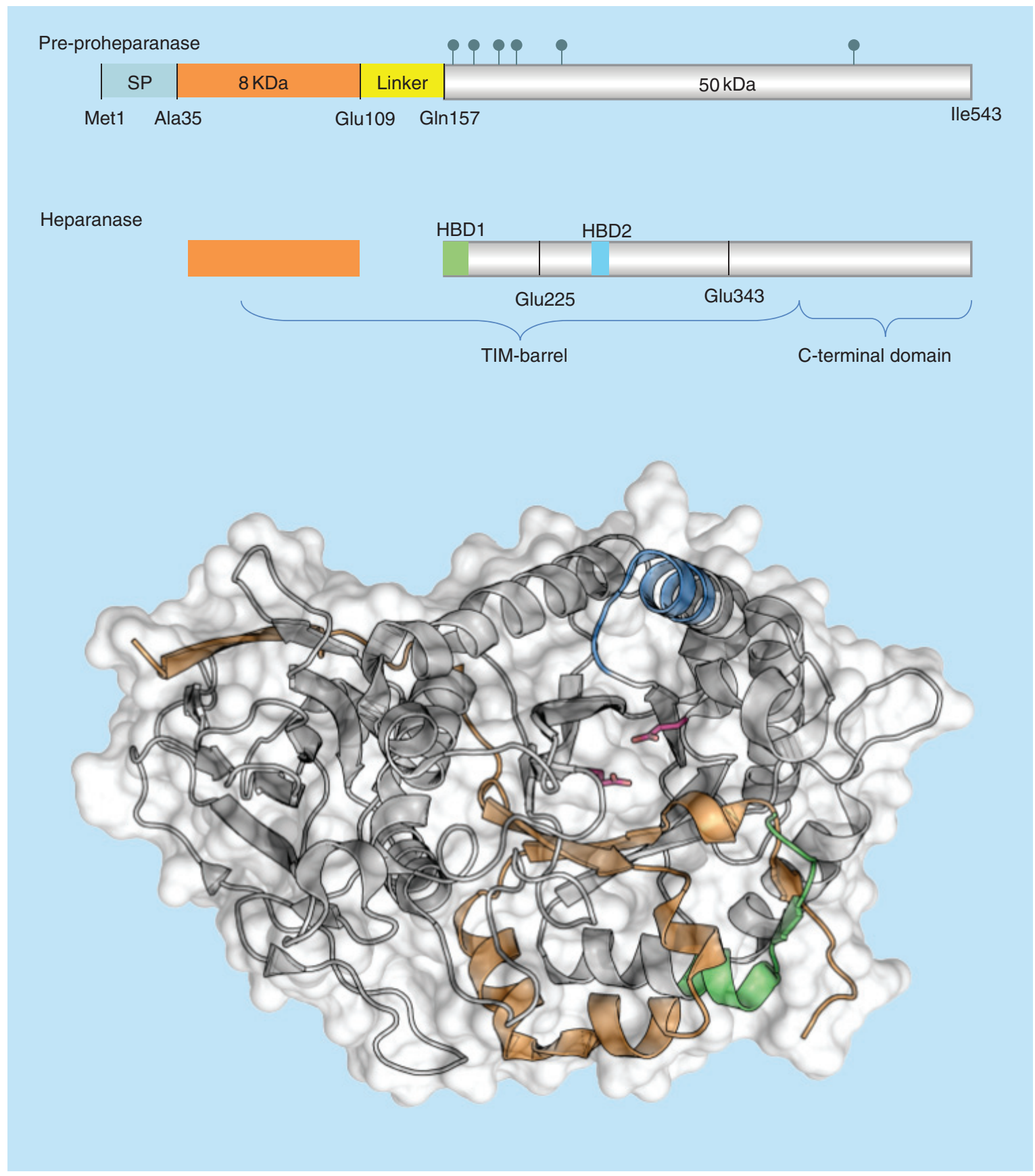

Figure 4. Heparanase sequence and structure. Top: diagram showing human preproheparanase and heparanase sequences. Green spots on the 50 kDa portion of preproheparanase represent predicted glycosilation sites. Bottom: 3D structure of human heparanase obtained from its crystal structure [32]. The $(\beta / \alpha)_{8}$-TIM-barrel domain is depicted on the right and the carboxy-terminal $\beta$-sandwich domain on top-left. In line with the scheme on top, the $8 \mathrm{kDa}$ chain is colored in orange, HBD-1 in green and HBD-2 in cyan. The catalytic amino acids Glu225 and Glu343 are represented in capped sticks with magenta carbons.

HBD: Heparin-binding domain; SP: Signal peptide.

of the $50 \mathrm{kDa}$ chain and is fundamental for the interaction with HS. In fact, a 15 amino acid-long peptide corresponding to HBD-1 (KKDC peptide) was shown to interact with heparins and HS and to inhibit heparanase enzymatic activity, likely competing with heparanase for the binding to HS. Simultaneous mutation of Lys158 and Lys161 in HBD-1 abolished heparanase interaction with HS, sustaining the critical role of this functional domain for substrate binding and for the design of heparanase inhibitors. HBD-2 comprises $\alpha$-helix 5 of the TIM barrel domain (Figure 4). A 10 amino acid-long peptide corresponding to HBD-2 
sequence (QPLK peptide) was able to interact with HS, even if with lower affinity than KKDC peptide. On the basis of these findings, it was hypothesized that the HS polysaccharide chain can occupy the active site of heparanase spanning the entire protein structure from HBD-1 to HBD-2.

HS is a highly sulfated and heterogeneous polysaccharide and heparanase cleaves the glycosidic bond between a $\beta$-D-glucuronic acid (GlcA) and the subsequent $N$-(sulfated)-D-glucosamine (Figure 5), releasing saccharide products characterized by appreciable molecular weight, still able to bind protein ligands. Heparanase substrate specificity has long been studied, by means of natural or synthetic polysaccharides and oligosaccharides, and the interpretation of the results has often been complicated by the heterogeneous nature of the substrates applied. Even if conclusive indications are still lacking, it was possible to clarify that the minimum heparanase recognition backbone is a trisaccharide and that heparanase cleavage does not depend on a defined saccharide sequence, but rather on the sulfation pattern, highlighting a regulating role of the neighboring saccharide sequences [40]. Heparanase seems to be characterized by substrate versatility, which allows to improve the efficiency of cleavage of the heterogeneous HS by maximizing the combinations of GlcA, $N$-sulfated- or $N$-acetylated-glucosamine (Glc) and iduronic acid (IdoA) on which the enzyme is effective. This plastic substrate specificity allows heparanase to adapt to differences in the composition of HS present in differ- ent physiological environments. It has been found that depending on the saccharide sequences released from its initial activity, heparanase is able to adopt either a consecutive or a gapped cleavage mode leading to different HS cleavage products. This double cleavage mechanism allows on one side the efficient degradation of HS in its mixed sulfated regions (by applying the consecutive cleavage mode), leading to the release of HS-bound macromolecules; on the other side, heparanase allows the formation of highly sulfated regions of HS (by applying the gapped cleavage mode) which are essential to promote signaling of growth factors and chemokines. Recently, the most common heparanase cleavage sites were identified based on profiling of the terminal structures created by heparanase digestion of HS chains of different origin and degree of sulfation [41]. Heparanase was shown to preferentially target the boundary of highly sulfated and mixed sulfated regions, producing oligosaccharides with an averaged sulfation degree on the reducing end side of the cleavage site approximately twice that of the nonreducing end side. In agreement with previous observations by Peterson and Liu [40], the newly cleaved HS chains have highly sulfated nonreducing end domains that potentiate growth factor (i.e., FGF2) activity. The most favorable heparanase cleavage site is present in the pentasaccharide sequence GlcNA6S-GlcA...GlcNS-HexA2S-GlcNS(6S) (HexA $=$ hexuronic acid; $\cdots=$ cleavable bond).

As crystal structures of heparanase became available only very recently $[32,42]$, in the last two decades

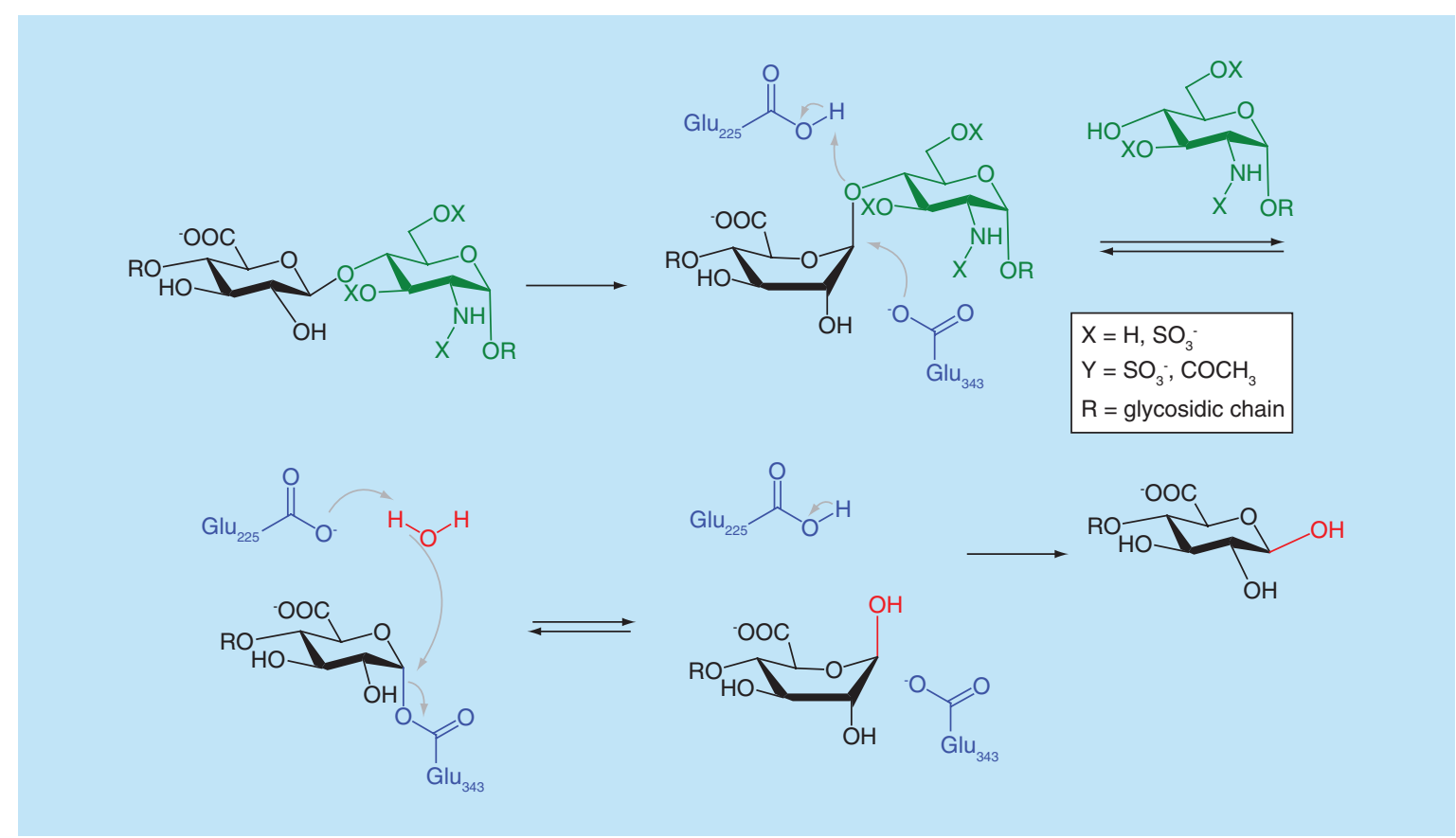

Figure 5. Proposed mechanism for the cleavage of the glycosidic bond by heparanase based on the retaining catalytic mechanism. 
numerous models of the 3D structure of human heparanase were built by homology modeling and used either to infer the putative binding mode of substrates or to rationalize structure-activity relationships (SARs) for inhibitors. These models were based on different template structures selected from crystallized glucosidases, like xylanase [43], endoglucanase [44], arabinofuranosidase [45] and endo-1,4- $\beta$-xylanase [46]. All models were able to reproduce the structure of the $(\beta / \alpha)_{8}$-TIM-barrel domain and to predict a basic amino acid binding groove. On the other hand, the catalytic site was far less accurate as it derived from template glycosidase structures with a different substrate specificity. Recently, a more suitable template became available, $\beta$-glucuronidase from Acidobacterium capsulatum, which belongs to the same family 79 of glycosyl hydrolases as heparanase. The new models of heparanase built from this template [47,48] properly predicted the geometry and the amino acidic composition of the catalytic site. This is particularly relevant for the protein portion (i.e., two consecutive backbone $\mathrm{NH}$ groups) constituting the recognition element for the acidic group of GlcA which was not properly identified in previous models.

The complexes of human heparanase co-crystallized with substrate analogs provided a structural rationale for the HS sulfation patterns necessary for heparanase catalytic activity in agreement with previously reported biochemical studies [40]. In particular, it was confirmed that sulfation is a key element for interaction with heparanase and that it represents a molecular signal that allows the cleavage of only certain glycan sites. Moreover, it was proposed that sulfate groups on the -2 and +1 saccharides represent anchor points for heparanase to prize open the substrate HS helix for a more efficient access of the catalytic residues to the glycosidic bond to be cleaved [32].

\section{Physiological functions \& pharmacological applications}

Heparanase can be considered as a double-edged sword or an animal with two tails, because under physiological conditions is present in a few tissues and has not a particularly relevant role, while in specific conditions, such as tumors where it is overexpressed, it becomes a very negative marker, contributing to creating all those conditions that, in turn, support severe pathological scenarios, such as tumor growth and metastases, or tissue inflammation, as discussed below. For this reason, some researchers have called it 'the monster' [49].

In most cases, highly relevant for example for tumor progression or inflammatory disorders, heparanase function is dependent on its catalytic activity on HS side chains of HSPGs, predominantly abun- dant in the ECM and cell surface and mainly involved in cell adhesion, growth and signaling, as well as in ECM assembly and growth factor storage. The biologic action of HS is likely based on several mechanisms involving: maintenance of structural integrity of the ECM (in particular, BMs) and of proper tissue organization, through its interaction with laminin, fibronectin and collagens [50]; modulation of the bioavailability and activity of chemokines, cytokines and growth factors (bFGF, VEGF, HGF and others), which are sequestered by HS in the ECM and cell surface, but are readily released by heparanase to promote cell proliferation, survival and motility [51-53]; control of their cellular uptake, or receptor-ligand complex formation $[54,55]$. For these reasons, enzymatic degradation and remodeling of HS alter the integrity and state of tissues and dramatically affect a variety of physiological and pathological processes, including tissue repair, cell adhesion, proliferation, survival and differentiation, tumor development and metastasis, angiogenesis, neurite outgrowth, inflammation and autoimmunity and others [9,56-59]. Besides, heparanase was also shown to exert multiple functions that are not mediated by its catalytic activity.

As previously anticipated, heparanase potentially affects a multitude of biological activities and of pathological conditions that can be schematically summarized in some relevant macro areas (Figure 6). Obviously, a wide panoramic of heparanase incidence for all these areas would be too pretentious and it is not the main goal of this review. We will highlight some key aspects for a few of these areas, and give only brief remarks for the others, linking them to relevant bibliographic references. Some publications for different macro areas, which might be of interest for the reader, are cited and briefly summarized in Supplementary Table 3.

\section{Heparanase in tumor progression \& angiogenesis}

A multitude of studies clearly demonstrates that heparanase, through its degrading action on HSPGs, is strongly involved in cancer progression both enhancing tumor cell dissemination and promoting neovascularization processes that, in turn, sustain invasion of metastatic cells. Numerous excellent reviews are available on this topic [60-64].

During tumor progression, heparanase enzymatic action contributes to the breakdown of extracellular barriers for cell invasion $[9,53,65,66]$ and also generates HS fragments which potentiate growth factor-receptor binding, dimerization and signaling [67]. The pivotal role of heparanase in promoting cancer invasion and extravasation of blood-borne tumor cells has been widely demonstrated $[3,68]$. 


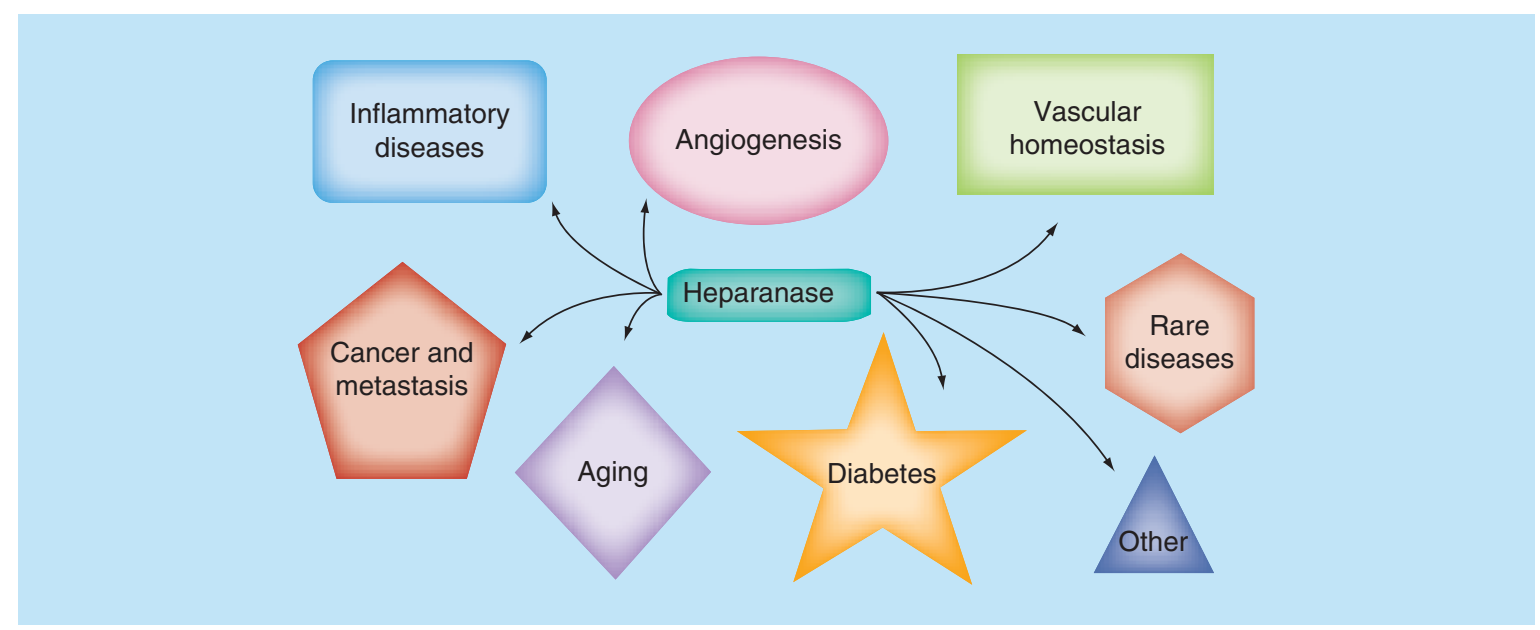

Figure 6. Heparanase is involved in many different pathological scenarios.

Heparanase also induces angiogenesis by modulating release and activity of several growth factors, ECM components and adhesion receptors. Usually, proangiogenic factors are sequestered, stabilized and protected by HSPGs. Heparanase, together with other degrading enzymes, through cleavage of HS chains may induce release of active HS-bound bFGF and VEGF, and promotes formation of HS-FGF-FGFR complexes that facilitate FGF receptor dimerization and signaling [9,69-71].

Notably, in addition to the well-documented catalytic aspects of its action, heparanase also exerts additional biological functions, highly relevant for tumor progression, such as facilitation of cell adhesion [72], regulation of gene transcription [73], regulation of exosomes secretion [74] and induction of signal transduction [75-77].

Heparanase is often upregulated in human tumors of various origins and associated with growth/aggressiveness of numerous cancer cell types [8,78-81]. Conversely, cancer cells lose their tumorigenic/metastatic abilities following heparanase gene silencing $[82,83]$.

Interestingly, in the last years, a novel splice variant of heparanase, termed T5, endowed with protumorigenic properties although it is a truncated and enzymatically inactive protein, has been described and characterized, and its clinical relevance in human renal cell carcinoma has been also reported $[33,84]$.

\section{Heparanase in inflammatory disorders}

The role of heparanase in inflammatory disorders has attracted much attention in the last years, and although a multitude of papers have been published on this topic, the precise mode of heparanase action in inflammatory reactions is still not completely elucidated, and experimental evidence suggests that heparanase may contribute alternatively to either augmenting or restraining inflammatory responses. A significant increase in the expression and enzymatic activity of heparanase has been reported in numerous inflammatory conditions, typically associated with degradation of HS and extensive remodeling of the ECM [59,85].

HS has been shown to modulate several steps in the inflammatory process through sequestration of cytokines and chemokines (including MIP-1 $\alpha$, RANTES, IL-2, 8 and 10 , IFN- $\gamma$, bFGF and TGF- $\beta$ ) in extracellular space, interaction (in the vessel wall) with L-selectin on the rolling leukocytes and facilitation of the rolling process, modulation of leukocyte transmigration through the endothelial cell layer and initiation of innate immune responses through interactions with Toll-like receptor 4 (TLR4) [86-91]. Consequently, HS enzymatic remodeling by heparanase can affect the architecture of the ECM and thereby facilitate recruitment, extravasation and migration of lymphocytes toward inflammation sites, and lead to activation of innate immune cells.

In this context, degradation of cell surface HS is particularly relevant for the inflammatory process. In fact, syndecans are differentially expressed in response to inflammatory stimuli and, undoubtedly, they play a key role in inflammatory events [57].

Noteworthy, upregulation of heparanase has been reported in various inflammatory disorders, such as rheumatoid arthritis [92], hepatitis C infection [93], chronic pancreatitis [94], Barrett's esophagus [81], Crohn's disease and ulcerative colitis [95,96], which are typically implicated in initiation of many cancer types in GI tract, pancreas, liver and other tissues, thus further highlighting the role of heparanase as a linking molecule between inflammation and cancer.

However, in some diseases, such as neuroinflammation, ECM integrity can promote the pathological conditions, while heparanase may exert a positive effect. When neuroinflammation was induced by systemic challenge with lipopolysaccharide or by localized cere- 
bral microinjection of aggregated amyloid- $\beta$ peptide in a transgenic mouse model overexpressing heparanase, all aspects of immune cell recruitment and activation were significantly attenuated in both inflammation models. These results suggest a key modulatory role of heparanase in neuroinflammatory responses [97].

\section{Heparanase in rare diseases}

In the last years, a key role of heparanase in establishing and supporting several rare disorders has been reported. For other pathologies, as in the case of fibrodysplasia ossificans progressiva, an involvement of heparanase is conceivable, even if not yet reported in the literature. Some representative cases are related to certain bone diseases, as discussed below.

\section{Hereditary multiple exostoses}

Hereditary multiple exostoses (HME) is a rare disease associated with development and growth of bony exostoses at the ends of the long bones, and caused by mutations in genes encoding for HS synthesizing enzymes EXT1 and EXT2, which lead to HS deficiency. This functional knockout of the exostosis chondrocytes' ability to synthesize HS chains leads to cytoskeletal abnormalities and chondrocyte disorganization associated with abnormal cell signaling and, ultimately, can cause growth retardation and deformities, as well as chronic pain and impaired motion, and which can progress to malignancy in 2-5\% of patients [98].

Exostosis formation seems to be affected by abnormal distribution of signaling factors and aberrant responsiveness of target cells to those same factors. Moreover, recently, a key role of heparanase has been reported in pathogenesis of HME. In fact, heparanase was shown to greatly stimulate chondrogenesis, a mechanism that could promote growth of exostoses, as well as bone morphogenetic protein signaling. Noteworthy, treatment of limb bud micromass cultures with the heparanase inhibitor roneparstat (SST0001) caused strong reduction of chondrogenesis, likely interfering with cell mobilization and cell-cell interactions needed by the limb mesenchymal cells to activate the chondrogenic program [99].

\section{Idiopathic avascular necrosis of bone}

Avascular necrosis (AVN) of bone, also known as aseptic necrosis or osteonecrosis, is a pathologic process that has been associated with numerous conditions and traumatic and nontraumatic factors [100]. The process is most often progressive, and results in joint destruction within a few months to 2 years in the majority of patients. In some cases, a direct damage to bone vasculature (e.g., femoral neck fracture) or direct injury of bone or marrow cells (bone marrow infarction) appear to be common causes of the disease. Anyhow, in many patients, the mechanisms by which this disorder develops are not yet understood [101]. To this regards, the involvement of heparanase in AVN of femur head has been recently reported, and inhibition of heparanase by heparins has been suggested as an innovative useful therapy [102].

\section{Fibrodysplasia ossificans progressiva}

Fibrodysplasia ossificans progressiva (FOP) is a rare and disabling genetic condition leading to congenital skeletal malformations and progressive heterotopic ossification, and characterized by heterozygous activating mutations in activin receptor IA (ACVRI)/ALK2, a bone morphogenetic protein (BMP) type I receptor [103].

BMPs are heparin-binding proteins and the developmental processes mediated by these proteins involve direct interactions with HSPGs, although the role of HSPGs on BMP-mediated signal transduction remains poorly understood [104]. O'Connell et al. showed that HSPG modulation of BMP signaling is altered in FOP lymphoblastoid cells, thus further supporting the hypothesis that altered HSPG-related BMP signaling may play a role in the pathogenesis of this disease [105]. However, as stated above, to date no direct evidence of a role for heparanase in FOP development has been reported.

Heparanase has been described to play a role in other nonskeletal disorders, such as AA amiloydosis and vulvodynia.

\section{AA amyloidosis}

AA amyloidosis is a rare but severe disease characterized by abnormal extracellular deposition of the serum A amyloid protein (SAA) peptide, in the form of fibrils, along with other components in various organs (i.e., spleen, liver and kidney) [106]. HS is suspected to participate in amyloidogenic pathology, as supported by its prominent accumulation in all amyloid deposits examined [107]. Recently, heparanase has been shown to have an impact on this disease and, in particular, on the resolution process [108].

\section{Vulvodynia}

Vulvar vestibulitis is the commonest subset of vulvodynia, and is a condition characterized by the sudden onset of a painful burning sensation and mechanical allodynia localized to the region of the vulvar vestibulus. Although the pathophysiology of vulvar vestibulitis is still unclear, a putative role of heparanase has been reported [109]. In fact, increased mast cell derived heparanase activity and intraepithelial hyperinnervation have been reported in tissues from women with 
localized vulvodynia with respect to healthy women. The function of heparanase, which is degranulated from mast cells, is to degrade the vestibular stroma and epithelial BM, thus facilitating proliferation of nerve fibers in the stroma and their subsequent intraepithelial extension.

\section{Heparanase \& integrins}

A topic still not sufficiently investigated and exploited is the relationship between overexpression of heparanase and integrins, although an increasing number of papers are highlighting this relationship. In the activation of the PI3K-AKT pathway by latent heparanase, the lack or inactivation of integrins ( $\alpha \mathrm{V} \beta 3$ or $\alpha 5 \beta 1)$ gave insufficient response while adhesion via either $\alpha \mathrm{V} \beta 3$ or $\alpha 5 \beta 1$ promoted heparanase-induced AKT phosphorylation, and a stronger effect was seen when both integrins were engaged. Stimulation of cells with heparanase enhanced their resistance against oxidative stress- or growth-factor starvation-induced apoptosis. Overall, there is an intimate crosstalk between the heparanase receptor(s) and integrins during induction of the prosurvival PI3K-AKT pathway by heparanase [110].

Moreover, the active role in tumor progression of ECM components has been put in relation to heparanase expression and integrins and, in this context, the upregulation of heparanase and the prominent expression of $\alpha \mathrm{V} \beta 5$ integrin might be considered as promising therapeutic targets [111].

Another condition where an overexpression of heparanase was observed was under hypoxic condition. HIF- $2 \alpha$ is active under hypoxic condition. Analyses of integrin expression revealed an important role for integrin- $\beta 1$ in the regulation of HIF- $2 \alpha$. Ischemic conditions significantly increased VEGFR2, Flk-1 in human umbilical vein endothelial cells (HUVECs). All angiogenic effects can be abolished by knockdown of integrin $\beta 1$, HIF- $2 \alpha$ and Flk-1 in HUVECs with selective shRNAs. These findings identify heparanase as a key regulator of angiogenesis [112].

It is the opinion of the authors that the integrins associated with heparanase represent a promising therapeutic approach such as for the treatment of bone metastases. To the best of our knowledge, integrin $\alpha \mathrm{V} \beta 6$ has not yet been investigated in depth in relation to the expression of heparanase but it remains a route that would deserve extensive studies [113].

\section{In vitro assays of heparanase activity}

In order to screen for effective heparanase inhibitors, a simple and reliable method suitable for measuring heparanase activity is required. In fact, the measurements of heparanase activity and inhibitor efficacy may vary substantially depending on the experimental conditions used, and are profoundly affected by several parameters involving, among the others, sensitivity, specificity and reproducibility of the method used for measuring heparanase enzymatic activity, source and nature of the substrate, source, purity, stability and specific activity of heparanase. It is noteworthy that in light of the growing interest of this target, an effort to choose common heparanase assay procedures would be of great value for selecting new potent and selective heparanase inhibitors on more directly comparable basis. Indeed, too often, known or newly discovered heparanase inhibitors are erroneously compared in terms of potency (usually expressed as $\mathrm{IC}_{50}$ value) without considering the different methods and experimental conditions used.

For several decades, multitudes of assays based on the use of HS for directly quantifying the rate of substrate cleavage, as a measure of heparanase enzymatic activity, have been developed. Differently from bacterial polysaccharide lyases that cleave heparin or HS chains generating an unsaturated product [114], the mammalian heparanases are hydrolases and, consequently, the products of their enzymatic activity on these substrates cannot be measured spectrophotometrically.

The majority of assays for many years were based on the use of solid-phase radiolabeled HS substrates. ECM-associated HSPG can be metabolically labeled by cultured cells with $\left[{ }^{35} \mathrm{~S}\right] \mathrm{Na}_{2} \mathrm{SO}_{4}[1,115]$ and the radiolabeled material released from the ECM, as direct consequence of HS chain degradation by heparanase, may be detected by gel-filtration analysis $[14,116]$. Alternatively, solid-phase heparanase assays have also been developed where HS polysaccharide purified from biological samples were chemically radiolabeled, for example, with $\left[{ }^{3} \mathrm{H}\right]$ acetic anhydride, or $\left[{ }^{3} \mathrm{H}\right] \mathrm{NaBH}_{4}$, and then attached to a solid support, with release of radiolabel from the solid support being a measure of enzyme activity [117-120]. Purified HS polysaccharides have been also labeled with nonradioactive markers such as, for example, fluorescein [121,122], europium [123] or biotin [124]. Anyhow, all these assays suffer from various severe disadvantages. First, in addition to being very expensive, HS polysaccharide purified from tissues or organs are very difficult to standardize as heparanase substrate due to their high structural complexity and diversity. Moreover, preparation of the labeled HS substrate, as well as separation of degradation products from the residual intact substrate, is a cumbersome and time-consuming procedure, and is prone to batch-tobatch variability even more because most of the HS molecules purified from tissues have been endoglycosidically processed. Additionally, solid-phase assays suffer from the disadvantage that the immobilized sub- 
strate may be less accessible to the heparanase enzyme, and the coupling of the labeled HS substrate to the support, through the reducing terminus of HS, may also be a complex procedure. In some cases, the substrate has been radiolabeled by iodination at naturally occurring glucosamine residues or by $N$-acetylation of the partially de- $N$-sulfated substrate $[125,126]$, but these procedures may also result in the masking or creation of new cleavage sites. Moreover, available experimental data do not allow ascertaining whether the relative rate for each of the cleavages is similar or whether the initial products of HS digestion may inhibit further substrate cleavage, thus behaving themselves as heparanase inhibitors. A possible consequence of this situation might eventually be the lack of linearity of the assay with respect to time.

In order to quantitate the enzyme activity, the labeled HS degradation products must be separated from residual labeled substrate. Gel filtration analysis by size-exclusion chromatography is very often used as a reliable method of the HS molecular weight shift $[115,127]$. The adoption of a mini column packed with chicken histidine-rich glycoprotein, which is a high-affinity heparin-binding protein, has been proven useful to improve the speed of the detection process [117]. Anyhow, because of the multiplicity of HS cleavage sites, which also accounts for the heterogeneity of fragment sizes ranging from 4.5 to $18.5 \mathrm{kDa}$, the use of chromatographic methods for separating low-molecular-weight fragments from the undigested substrate makes it difficult to accurately quantify heparanase activity and, more relevant, it is not suitable for screening large numbers of putative heparanase inhibitors.

Different groups, independently, have developed an ultrafiltration assay, which is based on the use of $\left[{ }^{3} \mathrm{H}\right]$-labeled HS as substrate and of Microcon (or Centricon) ultrafiltration devices to separate the heparanase-degraded fragments from the longer intact HS substrate, in aqueous buffer, thus allowing to test easily multiple compounds $[118,128]$. Furthermore, the enzymatic reaction during the aqueous phase allows kinetic analyses in standard conditions. Several analogs of the phosphosulfomannan angiogenesis inhibitor PI-88, for example, were shown to be competitive inhibitors of heparanase by this assay [129].

Many groups have established novel, alternative nonradioactive assay protocols. For example, $\mathrm{Xu}$ et al. developed an ELISA method suitable to measure the loss of HS in Matrigel using a monoclonal antibody against $\mathrm{HS}$ [130]. A similar approach has been also used to develop a multi-well format assay system where a biotinylated heparan sulfate glycosaminoglycan (HSGAG) substrate is covalently linked to the sur- face of 96-well immunoassay plates, and loss of biotin signal from the well surface, as a consequence of heparanase action, is then detected on incubation with peroxidase streptavidin followed by color development using 3,3',5,5'-tetramethylbenzidine as the peroxidase substrate [124]. A more sensitive high-throughput method for measuring heparanase activity and screening potential inhibitors has been then established by immobilizing dual (biotin- and FITC-) labeled HS on strepatividin-coated plates. Following degradation by heparanase, the labeled HS fragments are released into the reaction buffer and quantitated by fluorescence intensity measurement [131].

A more sophisticated homogeneous time-resolved fluorescence (HTRF) based assay has been developed by Enomoto et al. by using HS proteoglycan labeled with both biotin and europium cryptate as substrate, and directly measuring in the reaction buffer the timeresolved fluorescence generated upon complex with streptavidin that is cross linked with a fluorescence acceptor (like allophycocyanin) [132]. Based on this principle, a commercially available 384-well format HTS assay has been developed from Cisbio Bioassays and recently used for assessing the activity of heparin mimetic or derivatives [133,134].

An alternative approach used in some assays is that of quantifying the heparanase activity by measuring, through a specific HRP-conjugated anti-bFGF antibody, the residual amount of bFGF bound to HS substrate preadsorbed onto plates. Following degradation of the high molecular weight HS chains by heparanase, the smaller HS chains generated no longer adhere to the plate and this, in turn, causes a proportional reduction of the amount of growth factor still bound in the plate. A modified HS/bFGF 96-well plate assay has been used, for example, for performing an HS screening of a 50,000 compound library [135]. Different commercially available assay kits based on this principle have been developed.

Other commercial kits are based on the quantitative measurement of the interaction between biotinylated HS (substrate of the enzyme reaction) and the fusion protein CBD (cell binding domain of fibronectin) bFGF, which is already bound on a microplate. The amount of biotinylated HS bound is measured through the addition of an avidin-peroxidase (POD) conjugate and subsequent POD color development. Upon heparanase-mediated degradation of substrate, biotinylated HS is no longer able to bind to the CBD-bFGF fusion protein and is not detected. Anyhow, often these kits are primarily intended for the measurement of the activity of HS-degrading enzymes in cell extracts, cell culture medium, tissues or biological fluids rather than for assessing putative heparanase inhibitors and, hence, 
are not perfectly suitable for detailed kinetic analysis. Moreover, an adequate batch-to-batch consistency (mainly dependent on the peculiar nature of the substrate that, in turn, may affect reproducibility of the functionalization process of assay plates) and a high dynamic range represent critical aspects to be assessed before starting with a screening study.

To overcome some of the disadvantages associated with HS as substrate, a simple, accurate and robust microplate assay based on the cleavage of the synthetic heparin oligosaccharide fondaparinux has been developed by Hammond and coworkers [136]. Fondaparinux corresponds to the methyl glycoside of the antithrombin III (ATIII)-activating pentasaccharide sequence of heparin and is cleaved by heparanase to generate a reducing disaccharide, which can be quantitatively measured via a colorimetric or a fluorescence assay, the last by the fluorescent sensor polymer-H [137]. The assay, which recently has been further refined [138], has been successfully used by researchers of Progen for the screening of HS mimetics as potent heparanase inhibitors, resulting in the discovery of PG545 and structural analogs, and has been proven to be particularly suitable for kinetic analysis of heparanase inhibition [139]. Overall, major advantages of this rapid, simple and robust assay are: the use of a homogeneous, low-molecular-weight commercially available substrate that, in contrast to HS, is chemically defined, well available and has not to be labeled with any marker for detection; the accurate and reproducible quantification of heparanase activity in virtue of a single-site cleavage of the substrate; the lack of additional steps for separating digestion products; the suitability to perform a highthroughput screening of heparanase inhibitors with very low cost of material/reagents.

As widely outlined above, one of the major problems of many in vitro assays used for assessing putative heparanase inhibitors is represented by the heterogeneity of substrates and products. This is especially true for the numerous assays that use the high-molecular-weight HS as substrate. In order to overcome this problem, apart from fondaparinux, other structurally defined oligosaccharides have been synthesized and used as putative heparanase substrate [140-143]. As in the case of fondaparinux, often the advantages to use oligosaccharide substrates include the adoption of homogeneous and very cheap substrates, the lack of preliminary labeling of substrate with radioisotopes or similar markers, the ability to process easily multiple samples, the ease of handling and simplicity of the assay and the generation of hydrolyzed products that have no affinity for the active site of heparanase.

As mentioned at the beginning of this paragraph, another critical parameter for the heparanase assay is represented by the source and purity of the enzyme used. In fact, for many years, the lack of a consistent and constant source of highly pure and active heparanase enzyme, as well as of a reliable screening system, has been a severe problem to carry out successfully HTS programs aimed at identifying and developing inhibitors of heparanase catalytic activity. Active heparanase is a heterodimer in which a $50 \mathrm{kDa}$ protein works in concert with a tightly associated, but noncovalently linked, $8 \mathrm{kDa}$ peptide, and this makes very difficult each purification process irrespectively from the biological source and the protocol used. This scenario is further affected by the severe loss of enzymatic activity after one or more chromatographic steps, which are indispensable for purifying the enzyme with an adequate purity degree, and by the very low stability of the same enzymatic activity over time.

Natural heparanase can be theoretically purified from platelets [21], placenta [127], human hepatoma [20] and fibroblast cells [121] but the yields are usually quite low as well as the stability of enzymatic activity. Consequently, in many cases recombinant human heparanase expressed in insect or mammal cells and then purified from cell extracts or from the cell media, according to different protocols, is often used. To this end, for example, recombinant baculovirus has been generated using a dual expression vector engineered to produce both heparanase subunits $(8$ and $50 \mathrm{kDa}$ ), tagged for secretion [144]. Analogously, several groups independently have reported the cloning of human heparanase cDNA sequence and its expression in mammalian cells $[20,22,121]$ and, very interestingly, active heparanase single-chain proteins where the internal fragment between the $50-\mathrm{kDa}$ and the $8-\mathrm{kDa}$ subunits is replaced by a much shorter loop were generated and expressed in both mammalian and insect cells [35].

\section{Secondary cell-based or cell-free assays for assessing the activity of putative heparanase inhibitors}

Several cell-based assays suitable for assessing in vitro the activity of putative heparanase inhibitors have been described and, schematically, can be grouped as:

- Proliferation and cell viability assays with tumor and nontumor cell lines [145-147], also including assays with cells seeded on ECM [78] and colony forming assays [75];

- Angiogenesis assays, such as a Matrigel plug assay based on the use of heparanase-overexpressing lymphoma cells embedded in Matrigel and able to induce an intensive capillary network [67], classical Matrigel Invasion assays with BioCoat Matrigel invasion chambers or similar [146,147], assays based on the co- 
culture of endothelial and fibroblast cells for forming tubule structures [135], wound healing assays [147];

- Cell adhesion assay on fibronectin, collagen IV, laminin cellware dishes [147] or on ECM-coated wells [116].

Additional noncellular assays for further characterization of selected inhibitors might be the following:

- Assays aimed to measure the modulation of growth factors release from ECM [148];

- Surface plasmon resonance-based solution affinity assay (by means of BIAcore), for measuring the binding affinity of putative dual heparanase and angiogenesis inhibitors (such as analogs of phosphosulfomannans and other HS mimetic drugs) with respect to different proangiogenic growth factors (FGF-1/2, VEGF) [129,149,150].

\section{Strategies for heparanase inhibition}

The primary role of heparanase in sustaining pathological conditions has led to the search for molecules able to interfere with its biological activity, and in the last 20 years several classes of inhibitors were described, spanning from nucleic acids, proteins, monoclonal antibodies, polysulfated saccharides to small-molecule inhibitors (Figure 7). In this chapter the most relevant outcomes from the various classes will be outlined, while for a more detailed description the reader is referred to excellent reviews in the field $[61,151,152]$.

\section{Modified heparins \& other sulfated polysaccharides}

Heparin has a close structural analogy with HS and proved to significantly inhibit heparanase activity, likely due to competition with HS for binding to heparanase basic HBDs. Heparin contains some saccharide sequences recognized and cleaved by heparanase, and therefore it also acts as a substrate for this enzyme. However, its anticoagulant activity and the ability to displace HS-bound growth factors from their storage sites within the ECM and on cell membranes hampered its pharmacological application as heparanase inhibitor, and researchers focused their attention on the design of heparin analogs with reduced side effects. To this aim, a variety of structural modifications were evaluated, both on heparin functional groups and on its saccharide units, looking for the structural determinants for heparanase binding affinity and inhibitory potency. The general outcome from these SAR studies evidences that heparanase inhibition is more related to the degree of sulfation of heparin analogs, rather than to sulfation of particular positions, as both derivatives with 6-O-desulfated or 2-O-desulfated glucosamines retained the ability to inhibit heparanase. 2 - $O$-desulfation of iduronic acids did not affect inhibitory potency as well, while replacement of $N$-sulfate groups with $\mathrm{N}$-acetyl ones on glucosamines maintained a significant inhibitory potency only with a degree of acetylation lower than $50 \%$ [153]. C2-C3 ring opening of nonsulfated hexuronic acids led to glycol-split heparins, characterized by improved inhibitory potency, which was completely recovered for $N$-acetylated analogs. Glycol-split heparins are not substrates of heparanase, nor display anticoagulant activity. Their improved potency was attributed to the higher conformational freedom conferred by the split portions, which would favor the accommodation of the polysaccharide chain within the heparanase binding site [148]. Glycol-splitting technology led to the discovery of SST0001 and M402 which are currently being investigated in clinical trials (see the 'Inhibitors in clinical trials' section).

Besides heparin and its derivatives, other sulfated polysaccharides are endowed with heparanase inhibitory activity, and they were able to prevent the formation of metastasis or to reduce cancer cell invasion in in vitro tests. They comprise $\lambda$-carragenan, fucoidan, pentosan polysulfate, dextran sulfate, laminarin sulfate and a highly sulfated semisynthetic chitin derivative (SCM-chitin III) [154-156].

\section{Sulfated oligosaccharides \& related compounds}

One of the major limitations of polysaccharide inhibitors is their heterogeneous nature, both in chain length and composition, which could limit product characterization and standardization, as well as the interpretation of biological data. Sulfated oligosaccharide derivatives with significantly lower molecular weight than polysaccharides were prepared. Some are mixtures of oligosaccharides of different length, while others are single chemical entities.

As an example, the heparanase inhibitory potency of a series of sulfated malto-oligosaccharides with two to seven saccharide units was found to be comparable to that of heparin and roughly proportional to chain length [157]. PI-88 is a mixture of highly sulfated monophosphorylated sulfomannans with two to six saccharide units, mostly penta- and tetra-saccharides [157]. This compound inhibits heparanase activity, angiogenesis, tumor growth and metastasis and is currently being evaluated in clinical trials.

A series of highly sulfated analogs of PI- 88 was prepared based on a pentasaccharide mannose backbone. The rationale for this choice relied on the pentasaccharide component of PI-88, which is the major ( $60 \%)$ and the most active one, and on the observation that the terminal 6-O-phosphate group of PI-88 


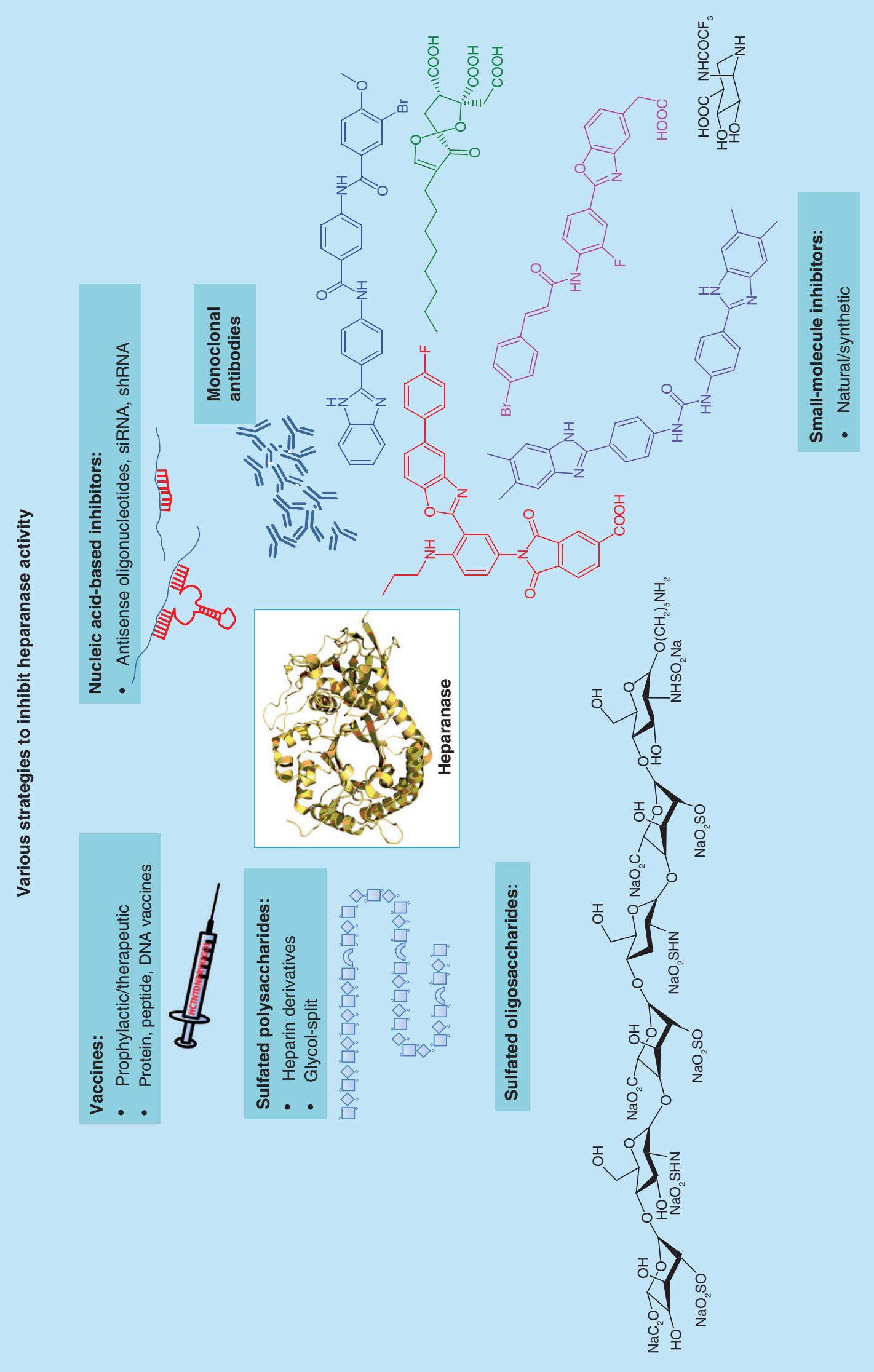

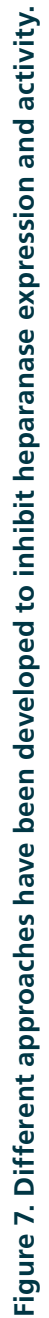


could be replaced by a sulfo group without activity loss. The compounds carried different substituents at the terminal anomeric carbon and were able to inhibit heparanase with a potency similar to that of the parent PI-88 $\left(\mathrm{IC}_{50} \sim 1-2 \mu \mathrm{M}\right)$ and to tightly bind to proangiogenic growth factors. The $n$-octyl derivative was the most promising compound, having three-times slower clearance than PI-88 [129].

Recently, three hexasaccharides characterized by the same (L-IdoA-D-GlcN) ${ }_{3}$ backbone and with different patterns of $\mathrm{O}$-sulfation and $N$-acetylation or -sulfation were described as endowed with limited ability to inhibit heparanase, with potencies in line with those of other low-molecular-weight heparins (LMWHs) [133]. Hexasaccharide 1 (Figure 8) showed $\mathrm{IC}_{50}=66.4 \mathrm{mg} / \mathrm{ml}$ in an HTR-FRET assay, emphasizing the importance of $N$-sulfates in specific interactions with heparanase.

Sulodexide is a mixture of glycosaminoglycans isolated from porcine intestinal mucosa, composed of LMWHs $(80 \%)$ and dermatan sulfate $(20 \%)$. Orally adsorbed, sulodexide is used since 1974 as an antithrombotic drug and is characterized by a prolonged half-life and limited effects on global coagulation and bleeding parameters [158]. Due to the presence of both glycosaminoglycan fractions, sulodexide potentiates the antiprotease activity of both antithrombin III and heparin cofactor II. Recent researches demonstrated its beneficial effects in the treatment of diabetic nephropathy, for which a new mechanism of action has been proposed based on the inhibition of heparanase [159].

Cyclitol-based pseudosugars coupled by alkyl or aryl linkers were synthesized as HS mimetics. They showed limited ability to inhibit heparanase activity, with the exception of a highly sulfated pentameric cyclitol (2, Figure 8) having a potency comparable to that of PI-88 [160].

\section{Anti-heparanase antibodies}

An efficient strategy to inhibit heparanase activity is based on antibodies raised against the protein. Polyclonal and monoclonal preparations of antibodies directed either versus the full-length protein or relevant fragments were used to investigate the role of heparanase in pathological settings or proposed as new potential therapeutic options. In early studies, rabbit IgG antibodies directed versus recombinant heparanase were able to significantly reduce invasiveness of ovarian carcinoma cells in in vitro experiments. Tumor cell invasion correlated with heparanase activity which could be regulated by microenvironmental redox conditions [161]. Rabbit polyclonal anti-heparanase antibodies directed versus the peptide sequence Arg382Phe398 reduced urinary protein excretion in a model of membranous nephropathy in rats. This nephropa- thy is characterized by elevated heparanase expression, and the results obtained with antibody administration supported heparanase inhibition as a novel strategy to reduce proteinuria [162]. The same antibodies were also tested in a model of accelerated anti-glomerular BM disease in rats, leading to a significant reduction of proteinuria [163]. A rabbit IgG neutralizing antibody raised against the peptide corresponding to the active site of platelet-derived heparanase (Gly215-Asp234) was found to significantly reduce the release of bFGF and neointima formation in a rat carotid balloon injury model, thus proposing neutralization of heparanase as a strategy to prevent restenosis following vascular injury [164]. Fragments KKFKNSTYSRSSVDV (1-15) and HCTNTDNPRYKEGDL (279-293) of the $50 \mathrm{kDa}$ subunit of human heparanase were selected as novel B-cell epitopes and multiple antigenic peptides (MAPs) of these epitopes were synthesized in a eightbranched form. Rabbit polyclonal antibodies directed versus the two MAPs were evaluated on human hepatocellular carcinoma (HCC) cells in vitro. They were able to reduce heparanase activity in the culture supernatant and to inhibit cell invasiveness, even if they showed no significant impact on cell cycle and growth curve [165]. A mouse monoclonal antibody which preferentially recognizes the $\mathrm{T} 5$ splice variant of heparanase was used to evaluate the role of $\mathrm{T} 5$ protein in renal cell carcinoma, as T5 is overexpressed in the majority of human renal cell carcinoma biopsies. T5 immunostaining was associated with tumor grade and size, supporting the clinical relevance of this splice variant which may complement the protumorigenic function of heparanase [166]. Recently, two human heparanaseneutralizing monoclonal antibodies (mAbs) were reported, one directed against the KKDC peptide and the other generated against the full-length heparanase protein. They were able to neutralize heparanase extracellularly and to decrease its intracellular content. When tested on mouse xenograft models of human lymphoma, these mAbs inhibited cellular invasion and tumor metastasis, the hallmarks of heparanase function. Interestingly, they attenuated tumor growth by targeting heparanase in the tumor microenvironment, and not by exerting a direct effect on tumor cells. The combined application of the two mAbs improved their capacity to restrain tumor growth, supporting the development of novel mAbs targeting other functional domains of heparanase or antibody combination with small-molecule inhibitors. Inhibition of heparanase activity by these mAbs might offer a novel and potentially safer way to exert an antitumor activity by obstructing the tumor microenvironment. Additionally, given the high specificity of these mAbs, they could represent a new pharmacological tool to 

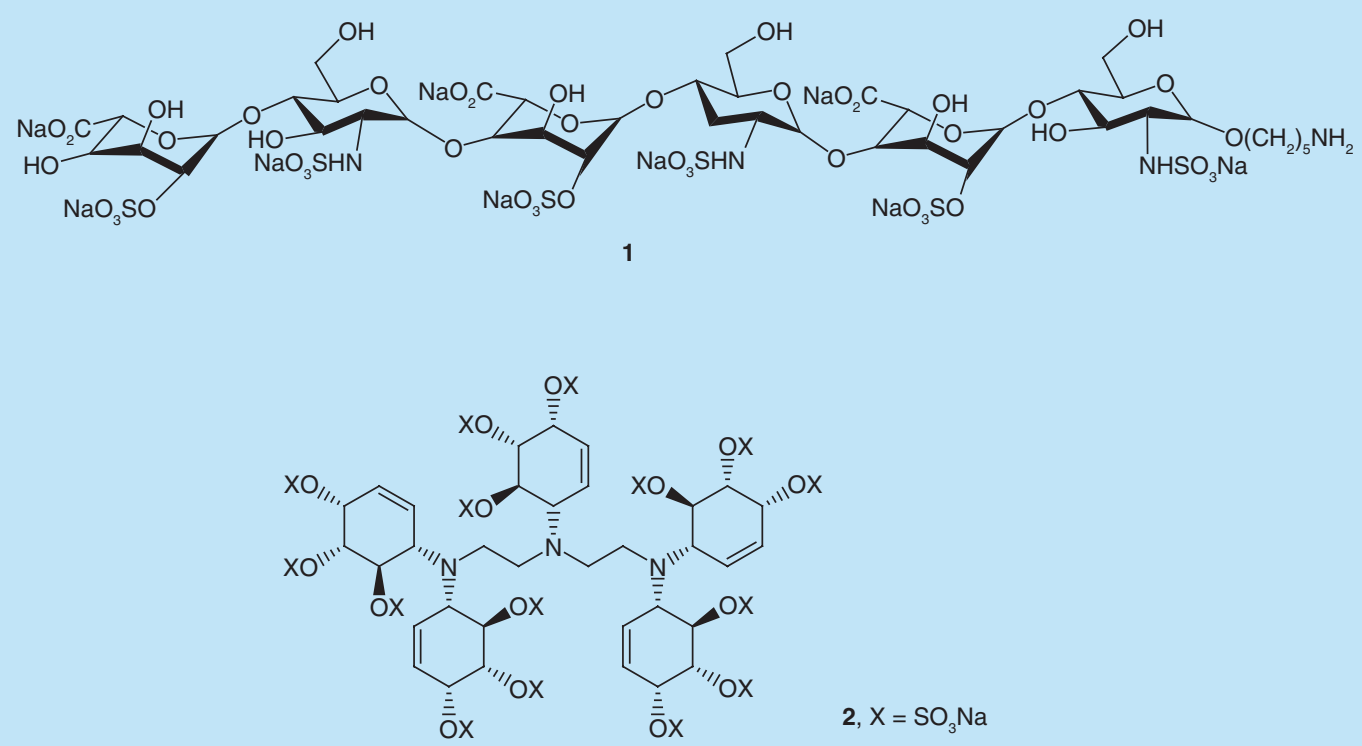

Figure 8. Structure of hexasaccharide (1) and cyclitol (2) heparanase inhibitors.

investigate the role of heparanase in other diseases [167].

\section{Vaccines}

In the last few years, vaccination against heparanase has been actively investigated, both as a therapeutic and a preventive strategy in the field of cancer pathologies. However, even if the results of this approach were overall successful, its evaluation is still limited to the preclinical setting.

In 2012, Haifeng Song group proposed a prophylactic heparanase DNA vaccine (plasmid DNA encoding the Hpse gene) delivered by electroporation for the treatment of cancer. This genetic vaccination strategy was tested in mice and macaques. The vaccine induced both humoral and cellular immunity, with production of heparanase-specific cytotoxic lymphocytes. Heparanase activity was inhibited in animal serum of immunized animals and the anti-heparanase antibodies from immunized mice inhibited heparanase activity in different cancer cell lines. Moreover, the immunized serum was able to decrease the invasiveness of a mouse melanoma cell line in vitro. The prophylactic vaccination significantly reduced tumor growth and metastasis in treated mice and prolonged their survival rate $[168]$.

A different, widely investigated vaccination strategy is based on the administration of dendritic cells (DCs, a type of antigen-presenting cell able to initiate antigenspecific immune responses) loaded with multiple antigenic peptides (MAPs). MAPs are based on the repetition of known epitopes of the target protein and are characterized by increased immunogenicity compared with the corresponding linear peptides. When this approach was applied to anti-heparanase vaccination, a lysine-based core matrix was coupled to several strips of epitope monomers to form a branch-like structure, improving specificity and stability of the epitope peptide.

Two four-branched MAPs based on murine heparanase T-cell epitopes, loaded into DCs, induced a strong immune response with increased rates of cytotoxic $\mathrm{T}$ lymphocyte (CTL)-mediated lysis of different mouse tumor cell lines. In vivo, they inhibited the growth of B16 murine melanoma in mice when administered before or after tumor establishment, supporting both an immunoprotective effect and an efficacious immunotherapy. Therapeutic vaccination also significantly increased mice survival rate [169]. A similar approach was also applied to the production of three four-branched MAPs based on CTL epitopes of human heparanase. DCs loaded with these MAPs induced human heparanase-specific CTL in vitro and ex vivo, eliciting cell lysis of different tumor cell lines [170]. Another eight-branched MAP, based on a B-cell epitope of human heparanase, was evaluated on human HCC cells and formation of metastasis. The antiserum produced by immunized rabbits was administered to nude mice bearing a murine model of HCC. The anti-MAP polyclonal antibodies reduced heparanase activity, decreased the expression of growth factors (e.g., VEGF) and microvessel density, markedly shrank the HCC volume, with no impairment of the functionality of heparanase-positive blood cells and organs (e.g., spleen and lymph nodes) [171,172].

Two heparanase multi-CTL epitope vaccines 
were generated and were loaded into DCs to induce heparanase-specific CTL. These CTL had increased IFN- $\gamma$ secretion and induced lysis of various cancer cells from different tissues in vitro and ex vivo with a potency significantly higher than the corresponding single peptides [173].

In order to consider the putative risks associated with immunotherapy approaches, we should keep in mind that heparanase is rarely expressed in normal mature tissues, such as liver, heart, lung, pancreas and so on, but it is usually expressed in some immune cell populations, such as macrophages, natural killer cells, activated $\mathrm{T}$ and $\mathrm{B}$ lymphocytes, neutrophils, dendritic cells and mast cells, where it plays key physiological roles and mediates extravasation and traffic to inflammatory sites. For this reason, theoretically, immunotherapy targeting heparanase for cancer treatment might induce side effects on the immune system. However, at least the multiepitope vaccine approach proved to be safe, as the heparanase-specific CTL did not induce lysis of autologous dendritic cells and lymphocytes [173], probably because the level of heparanase expressed in normal cells is below the threshold recognized by the heparanase-specific CTL.

\section{Nucleic acid-based inhibitors}

Different approaches have been attempted to inhibit heparanase gene expression through DNA- or RNAbased molecules. As in the case of antibodies, gene silencing was exploited for basic research, mainly to investigate the role of heparanase in malignancies, and to explore its potential for the development of novel therapeutic agents or diagnostic assays. Nucleic acidbased heparanase inhibitors include antisense oligonucleotides, ribozymes, aptamers, siRNAs, shRNAs and miRNAs. As a general outcome from studies based on this inhibition strategy, heparanase downregulation prevented proliferation and invasiveness of cancer cell lines of different origin, and reduced the growth of primary tumors, angiogenesis and metastasis in in vivo models. Some examples of these approaches are reported below. However, despite the significant results achieved in some preclinical animal models, no RNAi-based drug targeting heparanase expression has been tested in clinical trials.

Early studies described SdC28, a 28-mer phosphorothioate homopolymer of cytidine that produced a complete inhibition of heparanase purified from human placenta, inhibition of lung colonization of melanoma cells, but minimal effect on melanoma cell proliferation in culture. These results were likely due to a nonsequence-specific mechanism related to the polyanionic nature of the oligonucleotide, involving competition with $\mathrm{HS}$ on binding to heparanase active site [155]. Defibrotide, a polydeoxyribonucleotide of mammalian origin with antithrombotic and fibrinolytic properties, was reported to suppress the transcript, protein levels and enzymatic activity of human heparanase in myeloma cell cultures. In an in vitro tumor invasion assay, defibrotide was able to abrogate the increase of invasiveness produced by the addition of exogenous human heparanase in the culture or by transfection of multiple myeloma cells with heparanase construct [174]. In a recent study, magnetic nanoparticles composed of $\mathrm{Fe}_{3} \mathrm{O}_{4}$-dextran-anti- $\beta$-human chorionic gonadotropin were used as the vector to deliver a 20-mer heparanase oligodeoxynucleotide. This system was able to reduce heparanase mRNA and protein expression in choriocarcinoma cells, inhibit cell proliferation and invasiveness in vitro and to reduce transplanted choriocarcinoma tumor growth in nude mice [175].

Single-stranded DNA aptamers displaying high affinity and specificity for the active heterodimer of heparanase inhibited heparanase activity in an in vitro invasion assay, supporting a potential development as diagnostic or therapeutic agents [176]. The shortest (30 bases long) aptamer was able to inhibit heparanaseexpressing human oral squamous carcinoma cells (HSC-3) invasion, without exhibiting any cytotoxicity. This aptamer showed a reduced potential for nonspecific interactions with serum proteins and was stable in the presence of human serum, with no or minimal degradation by nucleases [177].

RNAi has been widely used to knock down heparanase gene for basic research or potential therapeutic purposes. One of the first heparanase gene silencing experiments with siRNA evaluated the role of heparanase in delayed-type hypersensitivity reaction in the mouse ear. After challenge with the hapten, the inflammatory response was significantly inhibited in the ears treated with the anti-heparanase siRNA. A similar effect was obtained with inhibitor SST0001, confirming the relevance of heparanase inhibition as an anti-inflammatory approach [178]. Hammerhead ribozymes and siRNA directed against human heparanase mRNA decreased the levels of heparanase expression in different tumor cell lines and reduced cellular invasion and adhesion in vitro. The ribozyme with best in vitro activity was tested in vivo, where it significantly inhibited lymphoma primary tumor vascularization, metastasis and mortality of tumor-bearing mice. siRNA maximal silencing effect was observed within $48 \mathrm{~h}$, leading to a significantly lower number of melanoma metastasis after administration to mice [179]. In a more recent study, siRNA molecules targeting either the promoter or the coding region of human heparanase were able to transiently reduce heparanase mRNA and pro- 
tein expression in hepatoma cells in vitro and to reduce cellular invasion and migration [180]. Two siRNAs targeting different coding regions of the heparanase gene were able to inhibit the proliferation and invasion capacity of liver cancer cells in vitro and tumorigenesis in nude mice [181]. siRNA and shRNA targeting heparanase transcription start site were able to induce transcriptional gene silencing in human cells. The shRNA was also tested on athymic nude mice in which it significantly reduced prostate tumor cell growth, invasion, metastasis and angiogenesis [182]. Recently, another anti-heparanase siRNA significantly reduced the invasion ability of Hepa1-6 cells and HCC growth in an orthotopic liver tumor model, leading to activation of cell apoptosis and autophagy [183].

A significant reduction of heparanase mRNA and protein expression levels could be also obtained with miRNA. Three miRNAs targeting different regions of heparanase mRNA reduced heparanase expression, attenuated cellular viability and proliferation of human malignant A375 melanoma cells and inhibited their adhesion, migration and invasion ability in vitro. One of these miRNAs suppressed lung metastasis of melanoma cells in mice [184]. In another study by the same research group, miR30-based shRNAs against heparanase were compared with shRNAs on human malignant melanoma cells in vitro and in vivo. The artificial miRNAs effectively abolished adhesion, migration and invasion of melanoma cells in vitro. They also suppressed tumor growth and lung metastasis of melanoma in vivo, with an improved safety profile compared with shRNA, leading to lower hepatotoxicity and lung injury [185].

\section{Small molecules}

Overall, there are no many researchers from industry or academia engaged in projects of discovery of heparanase inhibitors, especially for small-molecule inhibitors. Several groups published the results of their studies but, in general, it is difficult to make a SAR analysis. However, a limited number of teams are exceptions, developing important research programs that led to results still considered milestones in the medicinal chemistry of small molecule heparanase inhibitors [61].

The first heparanase inhibitor, a natural compound, was published by Shiozawa et al. in 1992 [186]. It was trachyspic acid (Figure 9), a metabolite produced by Talaromyces trachyspermus, and patented in Japan by Sankyo, Co., Japan [187]. This first report was followed by SAR studies [188], synthesis of racemic product and, finally, synthesis of enantiomerically pure product [189].

Suramin (Figure 9) is a synthetic polysulfonated naphthylurea initially developed as an antitrypanosomal drug (Chagas' disease), and more recently reported as a heparanase inhibitor with an $\mathrm{ID}_{50}$
$=46 \mu \mathrm{M}$ and a primarily noncompetitive mechanism of inhibition [190]. Suramin was evaluated in clinical trials as an anticancer agent, but clinical application was hampered by its severe side effects, likely related to its ability to interact with multiple cellular pathways. Many suramin analogs were prepared, some of them (NF127, NF145 and NF171) with higher potency and lower toxicity than the parent compound. These derivatives were anti-tumorigenic and antiangiogenic agents, inhibiting invasiveness of $70 \mathrm{~W}$ melanoma cell line [195]. Recently, high concentrations of suramin (300-600 $\mu \mathrm{g} / \mathrm{ml}$ ) were reported to decrease heparanase mRNA and protein expression and to inhibit ovarian and cervical cancer cell lines proliferation [196].

In 1994, in the Ciba-Geigy laboratories, novel 3-alkanoyl-5-hydroxymethyl tetronic acid derivatives were isolated from an Actinomycete strain in the course of a screening program for inhibitors of HIV-1 protease [197]. These compounds proved to be potent heparanase inhibitors. In 2004, researchers of the Japanese RIKEN Discovery Research Institute published their results on the lead compound RK-682 (Figure 9), as well as a SAR study aimed at obtaining more selective inhibitors. Their interest was focused on antitumor agents acting through a heparanase inhibition mechanism. RK-682 was found to display an inhibitory activity against heparanase and against several other enzymes. They investigated arylalkylation and benzylation of the 4-position of RK-682 and found 4-benzyl-RK-682 to possess a selective inhibitory activity for heparanase $\left(\mathrm{IC}_{50}\right.$ for heparanase $=17 \mu \mathrm{M}$ versus $\mathrm{IC}_{50}>100 \mu \mathrm{M}$ for other enzymes). 4-Benzyl-RK-682 was able to inhibit the invasion and migration of human fibrosarcoma HT1080 cells [191].

In 2002, the Israeli Insight Strategy and Marketing, Ltd. claimed an anti-heparanase activity of a number of scaffolds (3-6, Figure 9), in three patent applications [192-194].

One case study in the field of medicinal chemistry of heparanase inhibitors is represented by Oxford GlycoSciences (OGS) that, between 1999 and 2003, undertook a program aimed at developing small molecule heparanase inhibitors. A high-throughput screening (HTS) campaign allowed the exploration of a 50,000 compound library, identifying 2,3-dihydro1,3-dioxo- $1 H$-isoindole-5-carboxylic acid derivative 7 (Figure 10) as a novel hit compound with a heparanase inhibitory activity in the range of single digit $\mu \mathrm{M}$ $\left(\mathrm{IC}_{50}=8 \mu \mathrm{M}\right)$ and a modest cell-based antiangiogenic activity $\left(\mathrm{IC}_{50}=40 \mu \mathrm{M}\right)$. Starting from this scaffold, a SAR program was set up to identify more potent and selective inhibitors. After a series of specific changes off/on this scaffold, a new lead compound was identified, OGT2492 with improved antiangiogenic and enzyme inhibitory potency. Further optimization was 

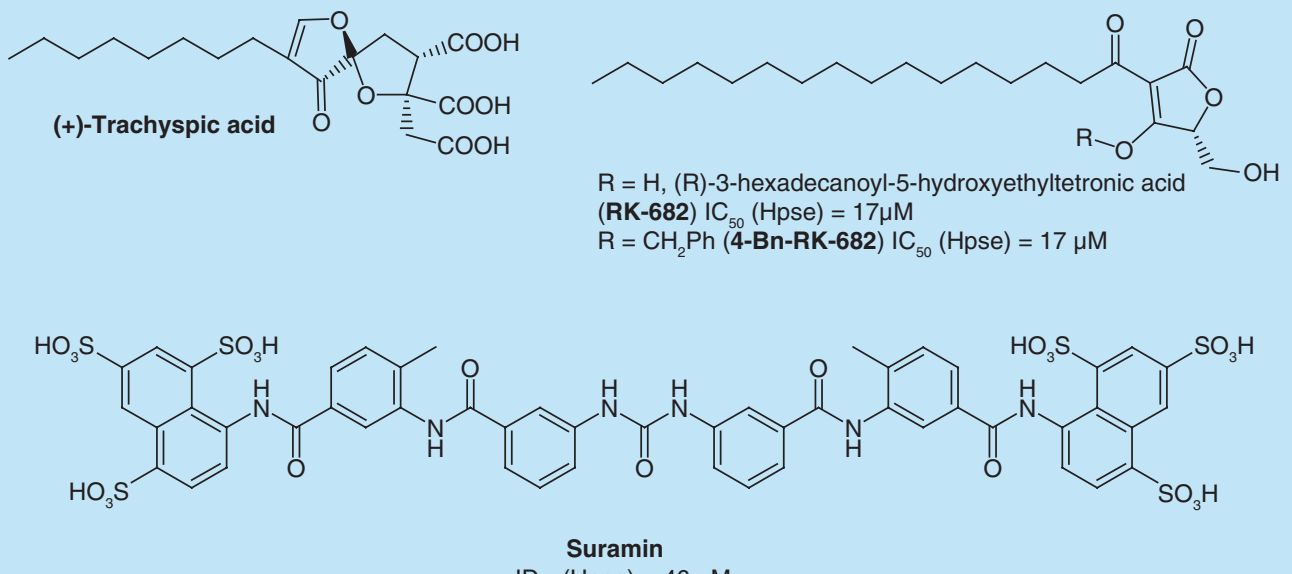

$\mathrm{ID}_{50}(\mathrm{Hpse})=46 \mu \mathrm{M}$

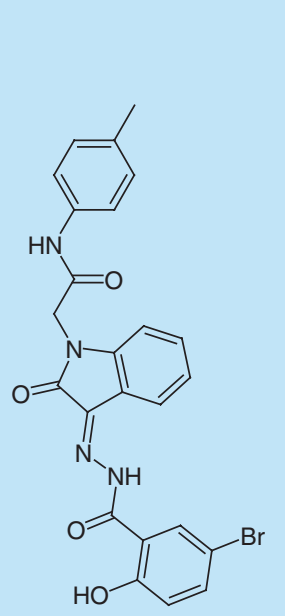

Indole derivative 3, $\mathrm{IC}_{50}(\mathrm{Hpse})=11 \mu \mathrm{M}$

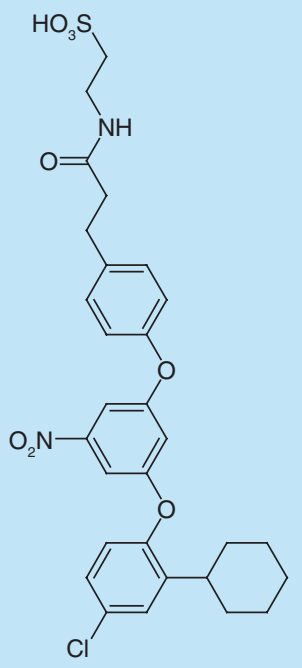

Diphenylether derivative 4, $\mathrm{IC}_{50}(\mathrm{Hpse})=5 \mu \mathrm{M}$

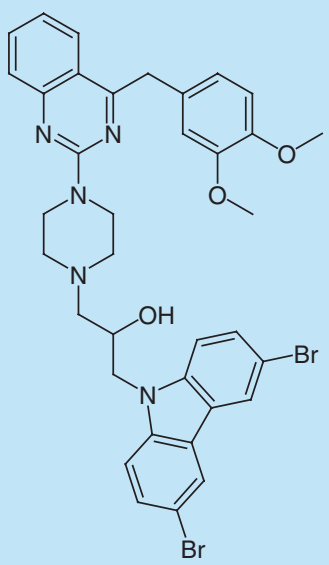

Carbazole derivative 5, $\mathrm{IC}_{50}($ Hpse $)=5 \mu \mathrm{M}$

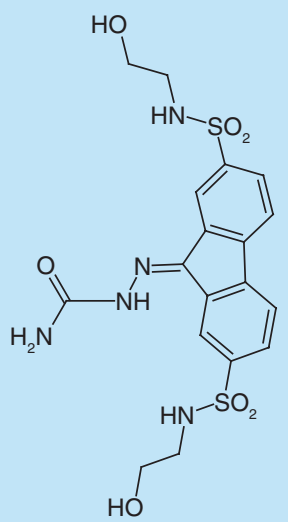

Fluorene derivative

6, $\mathrm{IC}_{50}(\mathrm{Hpse})=18.7 \mu \mathrm{M}$

Figure 9. Structures of small molecule heparanase inhibitors. Trachyspic acid, tetronic acid derivatives, suramin and compounds from Insight Strategy and Marketing, Ltd [186,190-194].

performed and new leads were identified with heparanase inhibitory activity as well as antiangiogenic activity in the submicromolar range (e.g., compound $\mathbf{8}$ in Figure 10) [135]. In a similar fashion to the 2,3-dihydro1,3-dioxo- $1 H$-isoindole-5-carboxylic acid series, OGS centered a second-phase research program on two new hit compounds, a furanylthiazole acetic acid (9) and a benzoxazole acetic acid (OGT2115) derivatives (Figure 10) [198]. Although Courtney et al. came up with an excellent SAR program, with selection of a few lead compounds with a suitable druggability profile, no in vivo studies were published and none of these molecules progressed to clinical trials. This reinforces the idea that there is a poor correlation between in vitro data and in vivo activity on this target; even less predictable is the clinical efficacy.
In 2006, new series of heparanase inhibitors based on a benzimidazol-2-yl scaffold were described by Imclone Systems Incorporated, with some derivatives (10-12, Figure 11) endowed with good inhibitory potency $\left(\mathrm{IC}_{50}\right.$ $\approx 0.1 \mu \mathrm{M})[120,199]$. Although some of these compounds were investigated in vivo against the B16-BL6 melanoma model showing an inhibition of lung metastasis by approximately $50 \%$ compared with the vehicletreated group, once again, to the best of our knowledge, no one of these compounds reached the clinical trials.

Another effort toward finding small molecule heparanase inhibitors was made by Gozalbes $e t a l$. They performed an in silico evaluation of a dataset of commercially available compounds based on both docking into a heparanase homology model and fitting to a pharmacophore model for known heparanase inhibitors. They 


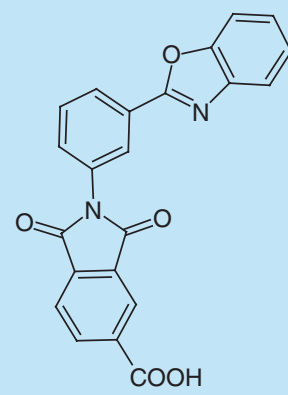

7

$\mathrm{IC}_{50}(\mathrm{Hpse})=8.0 \mu \mathrm{M}$ $\mathrm{IC}_{50}$ (antiangiogenesis) $=40 \mu \mathrm{M}$

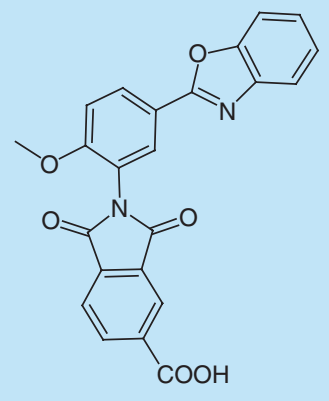

OGT2492

${ }^{\prime C}$ (Hpse) $=3.0 \mu \mathrm{M}$

$\mathrm{IC}_{50}$ (antiangiogenesis) $=2 \mu \mathrm{M}$

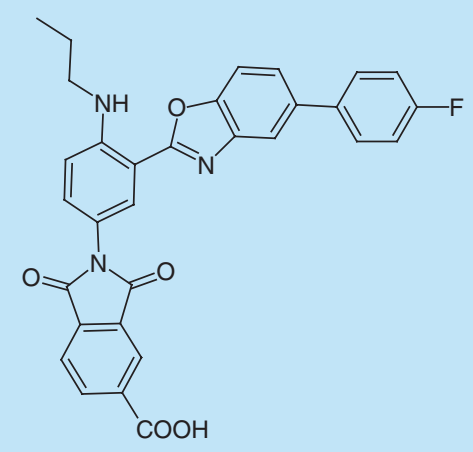

8

${ }^{\prime C} C_{50}$ (Hpse) $=0.5 \mu \mathrm{M}$

$\mathrm{IC}_{50}$ (antiangiogenesis) $=0.25 \mu \mathrm{M}$

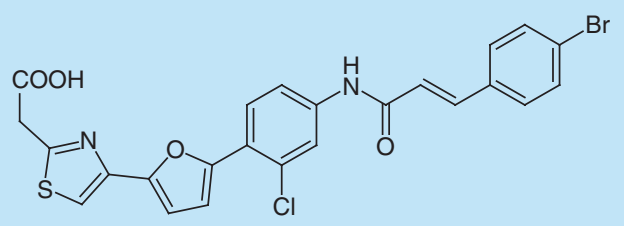

9

$\mathrm{IC}_{50}$ (Hpse) $=0.4 \mu \mathrm{M}$

$\mathrm{IC}_{50}$ (antiangiogenesis) $=1.0 \mu \mathrm{M}$

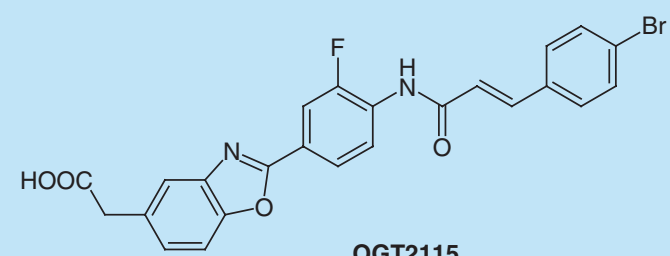

OGT2115

$I_{50}$ (Hpse) $=0.4 \mu \mathrm{M}$

$\mathrm{IC}_{50}$ (antiangiogenesis) $=1.0 \mu \mathrm{M}$

Figure 10. Heparanase inhibitors developed by GlycoSciences.

Data taken from $[135,198]$.

found that the antimalarial drug amodiaquine had $\mathrm{K}_{\mathrm{D}}$ $=52.6 \mu \mathrm{M}$ in surface plasmon resonance experiments. A series of amodiaquine derivatives was also prepared, but none of the compounds showed binding affinity higher than the parent compound [200].

In 2010, a novel sugar/pyranoside mimetic compound, DMBO or 2-(2,6-difluorophenyl)-5-(4methoxyphenyl)-1-oxa-3-azaspiro [5.5] undecane, Figure 11), was reported. This compound was designed to target multiple pathways involved in cancer progression and metastasis and its oxazine ring is described as a mimic of the pyranoside ring structure of HS. It was able to inhibit heparanase activity in a cell-free system with an $\mathrm{IC}_{50}=65 \mu \mathrm{M}$, but it inhibited the HSdegrading activity of LM8G7 osteosarcoma cells only at concentrations higher than $100 \mu \mathrm{M}$. DMBO was also able to bind several growth factors and cytokines (e.g., TNF- $\alpha$, VEGF) and exhibited strong anti-proliferative activity in vitro against osteosarcoma and ovarian tumor cell lines. It also showed antimetastatic and antiangiogenic activities [201].

Some substrate analogs are endowed with micromolar heparanase inhibitory potencies. Compound $\mathbf{1 3}$ (Figure 12) is an iminosugar isolated from the culture filtrate of Streptomyces nobilis SANK 60192. It showed an $\mathrm{IC}_{50}=12 \mu \mathrm{M}$ against human heparanase extracted from B16-BL6 melanoma cells, while its most known stereoisomer siastatin B (a neuraminidase inhibitor) was devoid of anti-heparanase activity [202]. However, compound $\mathbf{1 3}$ was not selective for heparanase, as it also inhibited bovine liver $\beta$-glucuronidase. More recently, a series of siastatin B derivatives characterized by a trifluoroacetamido substituent in position 6 of the piperidinecarboxylic acid scaffold were synthesized. Compounds 14-16 inhibited human heparanase with $\mathrm{IC}_{50}$ values of 28.99, 10.55 and $1.02 \mu \mathrm{M}$, respectively [203].

Overall, these small-molecule heparanase inhibitors are characterized by a broad structural diversity, in terms of molecular weight, relevant functional groups and physicochemical properties. A comprehensive SAR can be hardly envisaged for them, supporting the idea that several mechanisms are possible to inhibit this enzyme through compounds having different structures.

\section{Inhibitors in clinical trials}

As anticipated in the introduction, despite several classes of inhibitors were investigated as anti-heparanase, to date a very limited number of drugs are assessed in clinical trials and all of them belong to the class of polysaccharides, obtained through semisynthetic methods or total synthesis. Some of them have a defined structure, oth- 
ers are complex mixtures. The development of heparanase inhibitors has been recently reviewed by Hammond et al. [63], updated in Table 1 to the current clinical status.

For over 80 years, heparin was widely used as an anticoagulant, although its mechanism was understood much more recently [206]. In addition to the well-known anticoagulant effect, this natural polysaccharide was found to interact with a wide variety of biological pathways and systems, raising the possibility of a broader range of clinical applications, from inflammation to cancer. Some of the biological mechanisms underlying these activities include neo-angiogenesis and promotion of metastasis via - but not limited to - heparanase inhibition. Therefore, in recent decades, the most important challenge has been to separate the anticoagulant activity from other potential therapeutic activities of this polysaccharide. To this aim, numerous chemical modifications on the disaccharide backbone have been reported [207,208].

PI-88 - muparfostat (Figure 13), developed by the Australian Progen Pharmaceuticals, Inc., is a mixture of highly sulfated, monophosphorylated mannose oligosaccharides derived from the extracellular phosphomannan of the yeast Pichia (Hansenula) holstii, NRRL Y-2448, with potential antiangiogenic activity [209]. Muparfostat is a potent heparanase inhibitor, which may interfere with the heparanase-mediated degradation of HSPGs in ECMs, an important step in the metastatic process. In addition, muparfostat may also bind with high affinity to growth factors involved in neovascularization processes, such as VEGF, FGF1 and FGF2, thereby reducing their functional activities and inhibiting VEGF- and FGFdriven stimulation of tumor angiogenesis. Subsequently licensed to Medigen Biotechnology Corp., muparfostat advanced up to Phase III as an adjuvant treatment for patients with hepatitis virus-related HCC after surgical resection in Korea, Hong Kong and Taiwan. However, an interim analysis showed that the drug failed to meet the trial primary end point [210].

PG545 (Figure 13), developed by Progen as well, is a synthetic, fully sulfated HS mimetic with potential antiangiogenic and antitumor activity [205]. The antimetastatic activity of PG545 has been linked to inhibition of the enzymatic function of heparanase on HS chains from cell surface proteoglycans resulting, in turn, in inhibition of the interaction between HS and other ECM proteins as well as of the neovascularization process. The efficacy of PG545 in murine models of lymphoma was studied in detail and its antitumor effects were found to be dependent on natural killer cell activation that, in turn, requires involvement of Toll-like receptor 9 [211]. PG545 was also able to inhibit the growth of tumor xenografts produced by Burkitt's, diffuse and follicular lymphoma cells [167]. It is currently being trialed in a Phase I study against solid tumors [212,213]. After a first phase where PG545 was administered subcutaneously, the delivery route was discontinued due to side effects at the injection site, and now the drug is administered intravenously.

SST0001 - roneparstat (Figure 13), is being developed by Sigma-Tau Research Switzerland S.A. and belongs to the ' $N$-acetyl reduced oxyheparins'. It is a semisynthetic heparin-like polymer that through rational chemical engineering modifications, including a step of reduction-oxidation of a few residues (uronic acid) in addition to a step of hyperacetylation, is transformed into a $15-25 \mathrm{kDa}$ glycol-split $N$-acetyl heparin with reduced anticoagulant properties and a powerful anti-heparanase activity [148]. Recently, dose-inhibition curves were analyzed to investigate the kinetics of

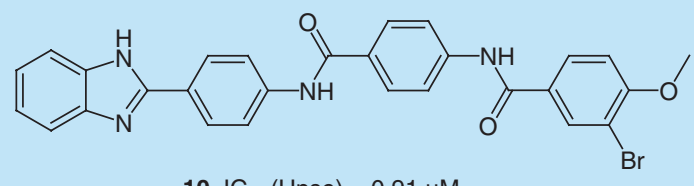

$10, \mathrm{IC}_{50}(\mathrm{Hpse})=0.91 \mu \mathrm{M}$

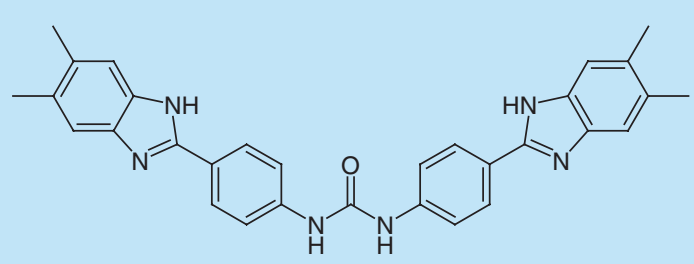

12, $\mathrm{IC}_{50}(\mathrm{Hpse})=0.075 \mu \mathrm{M}$

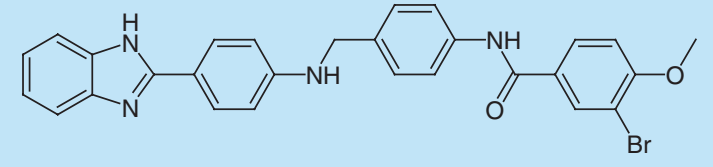

$11, \mathrm{IC}_{50}(\mathrm{Hpse})=0.23 \mu \mathrm{M}$

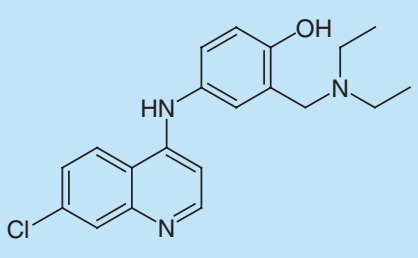

Amodiaquine

$\mathrm{k}_{\mathrm{D}}(\mathrm{Hpse})=52.6 \mu \mathrm{M}$

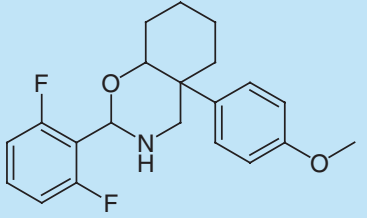

DMBO

$\mathrm{IC}_{50}(\mathrm{Hpse})=65 \mu \mathrm{M}$

Figure 11. Chemical structures of benzimidazol-2-yl-heparanase inhibitors, amodiaquine and DMBO. 


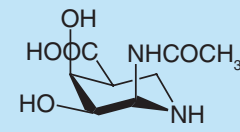

13

$\mathrm{IC}_{50}(\mathrm{Hpse})=12 \mu \mathrm{M}$

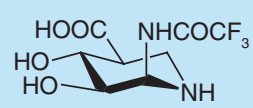

14

$\mathrm{IC}_{50}(\mathrm{Hpse})=28.99 \mu \mathrm{M}$

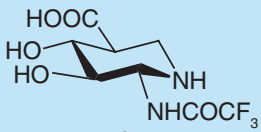

15

$I_{50}($ Hpse $)=10.55 \mu \mathrm{M}$

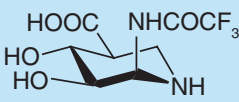

16

$\mathrm{IC}_{50}(\mathrm{Hpse})=1.02 \mu \mathrm{M}$

Figure 12. Structures of iminosugars endowed with anti-heparanase activity.

heparanase inhibition by roneparstat. The study confirmed the high potency of roneparstat $\left(\mathrm{IC}_{50} \approx 3 \mathrm{nM}\right)$ and highlighted a different behavior of the inhibitor depending on its concentration, suggesting the existence of multiple protein-ligand interaction modes [48]. Roneparstat dowregulates HGF, VEGF and MMP-9 expression, suppresses angiogenesis and was found to diminish heparanase-induced shedding of syndecan-1, which is known to be a potent promoter of myeloma growth. While roneparstat proved to be active in some tumor models [214,215], in particular against breast cancer bone metastasis (Sigma-Tau data on file) and lapatinib-resistant metastases to the brain [216] or to inhibit radiation-enhanced invasiveness of pancreatic carcinoma [217], its possible therapeutic role has been largely studied in multiple myeloma, where its mechanism of action could also play a role in dual targeting the tumor and its microenvironment [218]. In preclinical murine

\section{Table 1. Heparanase inhibitors in clinical trials. $\mathrm{IC}_{50}$ values ${ }^{\dagger}$ (from literature) are also indicated.}

\begin{tabular}{|c|c|c|c|c|c|c|}
\hline $\begin{array}{l}\text { Code name } \\
\text { (INN) }\end{array}$ & $\begin{array}{l}\text { Developed by } \\
\text { (country) }\end{array}$ & $\begin{array}{l}\text { Mechanism of } \\
\text { action }\end{array}$ & $\begin{array}{l}\text { Clinical } \\
\text { trials }\end{array}$ & $\begin{array}{l}\text { Therapeutic } \\
\text { indication }\end{array}$ & Note & Ref. \\
\hline $\begin{array}{l}\mathrm{Pl}-88 \\
\text { (muparfostat) }\end{array}$ & $\begin{array}{l}\text { Progen } \\
\text { Pharmaceuticals } \\
\text { (Australia) } \\
\text { Licensed to: Medigen } \\
\text { Biotech Corp. } \\
\text { (Taiwan) }\end{array}$ & $\begin{array}{l}\text { Heparanase } \\
\text { inhibitor } \\
\left(\mathrm{IC}_{50}: \sim 8 \mathrm{nM} \text {; }\right. \\
64 \mathrm{ng} / \mathrm{ml}) \\
\text { FGF1-2 antagonist } \\
\text { VEGF receptor } \\
\text { antagonist }\end{array}$ & Phase III & $\begin{array}{l}\text { Hepatocellular } \\
\text { carcinoma }\end{array}$ & $\begin{array}{l}\text { Phase III study } \\
\text { interim analysis } \\
\text { failed primary end } \\
\text { point (disease-free } \\
\text { survival) }\end{array}$ & {$[157,204]$} \\
\hline PG545 & $\begin{array}{l}\text { Progen } \\
\text { Pharmaceuticals } \\
\text { (Australia) }\end{array}$ & $\begin{array}{l}\text { Heparanase } \\
\text { inhibitor } \\
\left(\mathrm{IC}_{50}: \sim 10 \mathrm{nM} \text {; }\right. \\
25 \mathrm{ng} / \mathrm{ml}) \\
\text { Angiogenesis } \\
\text { inhibitor }\end{array}$ & Phase I & Solid tumors & $\begin{array}{l}\text { Earlier suspended } \\
\text { due to local injection } \\
\text { site reactions } \\
\text { seen in patients; } \\
\text { then the route of } \\
\text { administration was } \\
\text { changed, from sc. } \\
\text { to iv. }\end{array}$ & {$[204,205]$} \\
\hline $\begin{array}{l}\text { SST0001 } \\
\text { (roneparstat) }\end{array}$ & $\begin{array}{l}\text { Sigma-tau Research } \\
\text { Switzerland SA } \\
\text { (Switzerland) }\end{array}$ & $\begin{array}{l}\text { Heparanase } \\
\text { inhibitor } \\
\left(\mathrm{IC}_{50}: \sim 3 \mathrm{nM} \text {; }\right. \\
60 \mathrm{ng} / \mathrm{ml}) \\
\text { Dowregulation } \\
\text { of HGF, VEGF and } \\
\text { MMP-9 }\end{array}$ & Phase I & $\begin{array}{l}\text { Advanced } \\
\text { multiple myeloma } \\
\text { (combo with } \\
\text { dexamethasone) }\end{array}$ & & [48] \\
\hline $\begin{array}{l}\text { M-402 } \\
\text { (necuparanib) }\end{array}$ & $\begin{array}{l}\text { Momenta } \\
\text { Pharmaceuticals (USA) }\end{array}$ & $\begin{array}{l}\text { Heparanase } \\
\text { inhibitor } \\
\left(\mathrm{IC}_{50}: \sim 800 \mathrm{nM} \text {; }\right. \\
5500 \mathrm{ng} / \mathrm{ml}) \\
\text { Inhibitor of FGF2, } \\
\text { SDF-1 } \alpha, \text { VEGF, } \\
\text { P-selectin } \\
\text { Apoptosis stimulant }\end{array}$ & Phase I/II & $\begin{array}{l}\text { Pancreatic cancer } \\
\text { (combo with nab- } \\
\text { paclitaxel and } \\
\text { gemcitabine) }\end{array}$ & & [150] \\
\hline
\end{tabular}




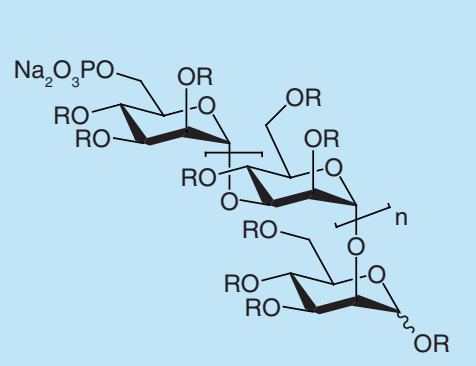

PI-88, muparfostat

$\mathrm{n}=0-4, \mathrm{R}=\mathrm{SO}_{3} \mathrm{Na}$ or $\mathrm{H}$

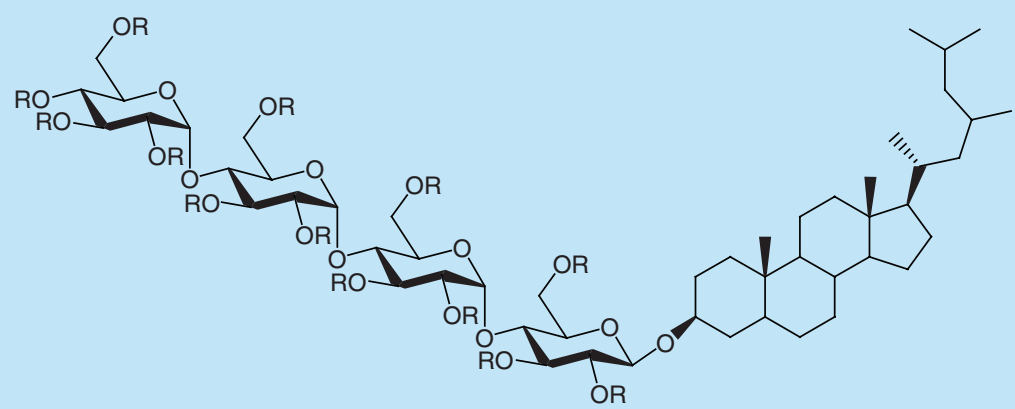

PG545, $\mathrm{R}=\mathrm{SO}_{3} \mathrm{Na}$

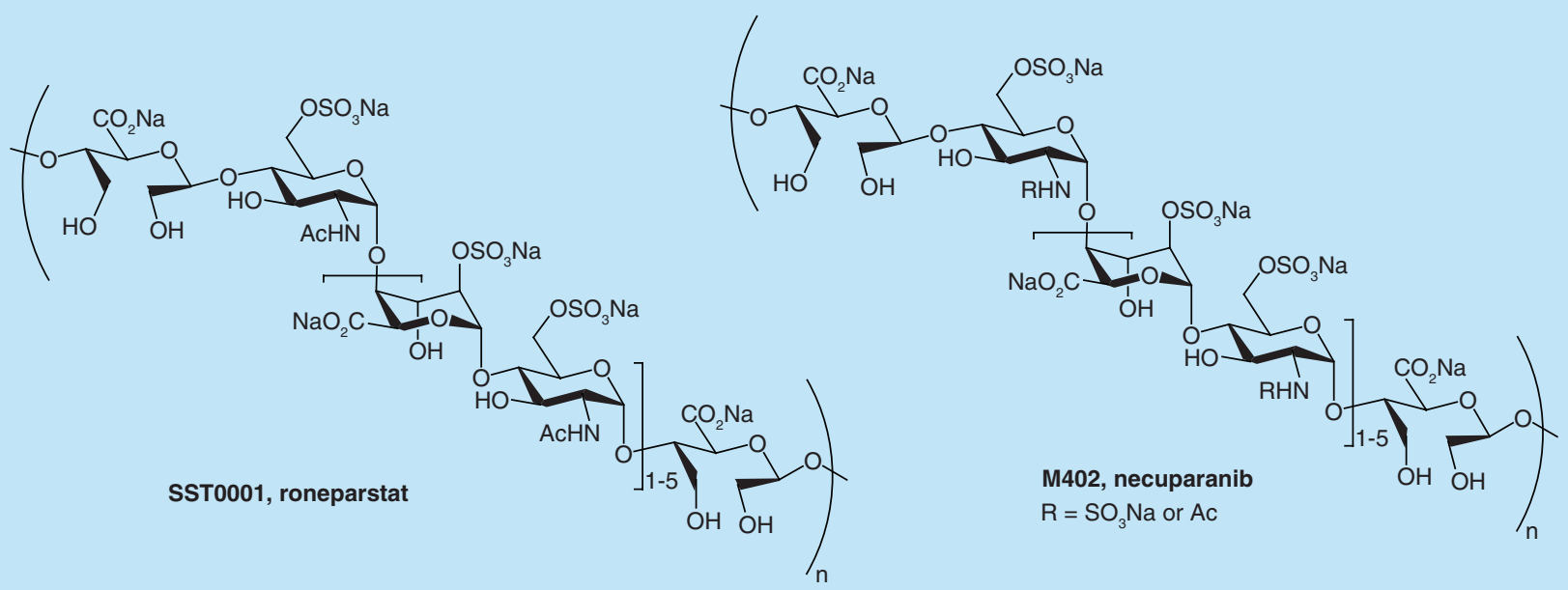

Figure 13. Molecular formulas of heparanase inhibitors in clinical trials.

models roneparstat, administered either alone or in combination with dexamethasone, showed a significant anti-myeloma effect in multiple myeloma mice xenograft models [218]. Moreover, preclinical data showed a synergistic anti-myeloma effect in mice bearing a bone homing highly aggressive myeloma model expressing high levels of heparanase (CAG-HPSE), when roneparstat was combined with proteasome inhibitors or melphalan. These data are of particular interest since high heparanase-expressing myeloma cells are less susceptible to the cytotoxic effects of bortezomib or melphalan, and an increase in heparanase gene expression has been shown in multiple myeloma patients after exposure to chemotherapy [219]. Roneparstat is currently being tested in association with dexamethasone in a Phase I dose finding study assessing safety and tolerability, in patients with advanced multiple myeloma. Encouraging preliminary data have been recently reported [220].

M402 - necuparanib (Figure 13), developed by the American company Momenta Pharmaceuticals, is another semisynthetic heparin-like polymer obtained by controlled depolymerization of unfractionated heparin with nitrous acid and then sequential periodate oxida- tion and borohydride reduction [150]. The final glycolsplit HS mimetic, with low molecular weight $(5-8 \mathrm{kDa})$, showed a reduced anticoagulant activity and an antimetastatic and anticancer activity. Its mechanism of action is probably related to inhibition of multiple heparin binding factors, including VEGF, FGF2, SDF1a, P-selectin and heparanase, involved in tumor growth and metastasis. In preclinical murine models necuparanib, administered either alone or in combination with cisplatin or docetaxel, showed a significant antimetastatic activity. Necuparanib is currently under a Phase II trial investigation, with nab-paclitaxel and gemcitabine, in patients with pancreatic cancer. Recently, the trial required an amendment for diagnosis and management of thrombocytopenia following recommendations from its independent Data Safety Monitoring Board (DSMB) because of a limited number of specific toxic events [221].

\section{Conclusion}

Heparanase is a multifaceted enzyme, involved in multiple critical biological functions, that has generated a progressively growing interest in both academic and industrial research. This is also witnessed by the 


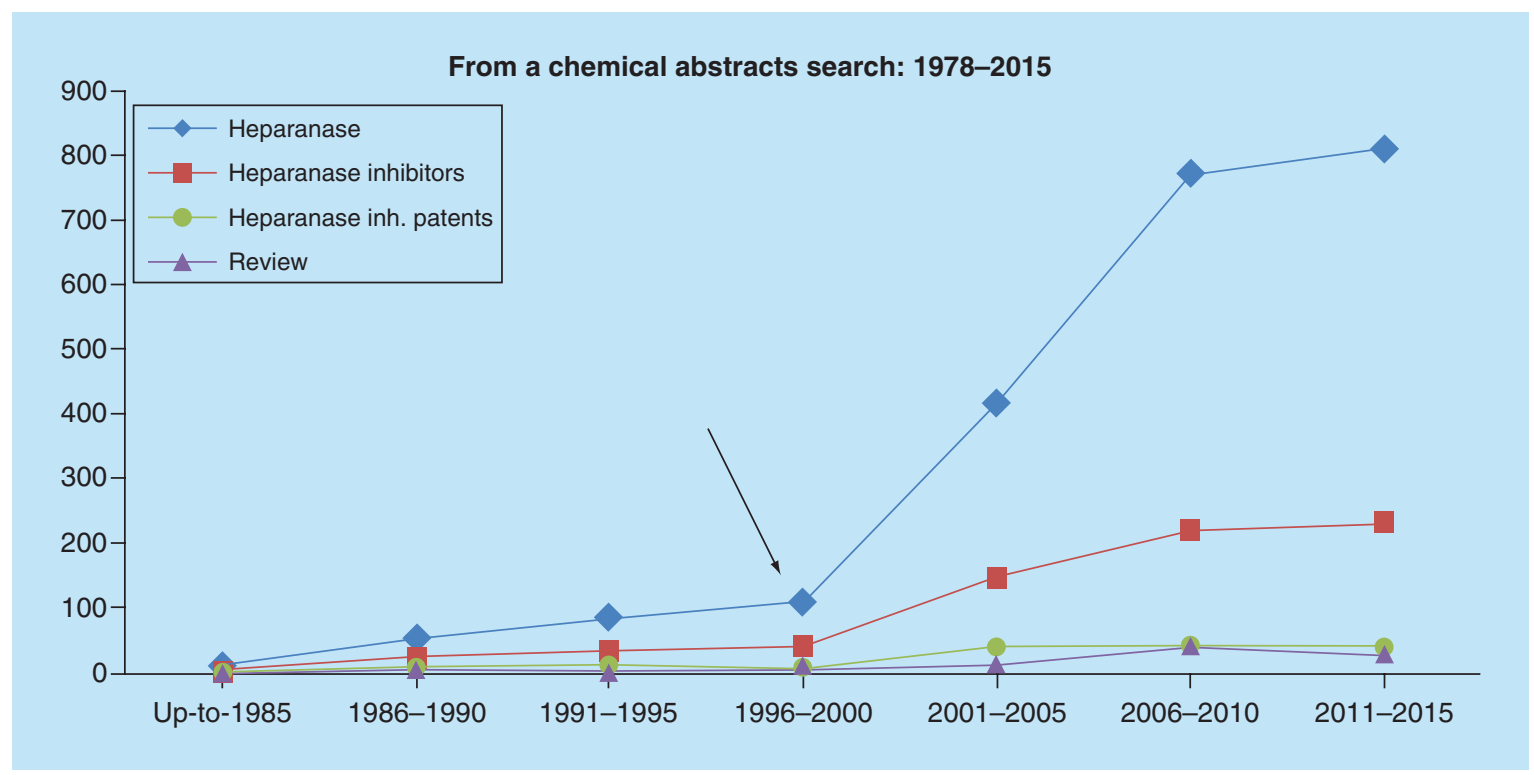

Figure 14. Chemical Abstract (SciFinder ${ }^{\oplus}$ ) data analysis. Distribution of patents, research papers and reviews concerning heparanase and heparanase inhibitors from 1978 to 2015, divided into 5-year-long periods. The arrow indicates the cloning of heparanase gene (1997-1998). See Supplementary Table 1 for more details.

number of patents and papers on heparanase and its inhibitors appeared in the last four decades (Figure 14 \& Supplementary Tables 1 and 2).

By virtue of its peculiar enzymatic properties, heparanase is the only known mammalian endo- $\beta$-Dglucuronidase capable of cleaving glycosaminoglycan polysaccharide side chains, such as the HSPGs localized on the cell surface, in basement membranes and throughout the ECM of mammalian tissues. The wide distribution of heparanase substrates and their evolutionary conservation demonstrate the vital importance of these molecules in cell development and function, and highlight the critical role of heparanase in ECM remodeling and in a multitude of both normal and disease-related processes, as diverse as inflammation, blood coagulation, wound healing, angiogenesis and tumor cell invasion.

Noteworthy, heparanase has been recently reported to play a fundamental role in many other pathologies, such as diabetic nephropathy, osteolysis in bone metastases as well as in other bone tissue related pathologies, atherosclerosis, cardiovascular disorders and cutaneous aging. The panorama of diseases affected by heparanase expression and activity also includes the so-called rare diseases, such as AA amyloidosis, hereditary multiple exostoses and idiopathic avascular necrosis of bone as well as pathologies that are not rare in terms of incidence, but are rarely diagnosed, such as vulvodynia. More recently, Vlodavsky et al. have established a role for heparanase in modulating autophagy in normal and malignant cells, enhancing tumor growth and chemoresistance by promoting autophagy [222]. Very interest- ingly, heparanase has also a prognostic value; in fact, strong expression of this enzyme is often associated with a less favorable prognosis for patients with different types of tumors. To this regard, heparanase expression level has been recently proposed as a potential biomarker associated with oral cavity tumors [223,224].

Although heparanase was discovered more than 30 years ago and was cloned at the end of the last century, no drug able to inhibit or modulate its functions has been registered. However, the biological role of heparanase has been widely demonstrated in numerous studies, and the availability of a drug able to specifically modulate the activity of this enzyme would be a powerful pharmacological option for many therapeutic indications. To date, only four drugs have been tested in different phases of clinical trials. They are polysaccharide derivatives of natural origin, such as muparfostat and roneparstat, or obtained by synthesis, as PG545, currently evaluated as anti-cancer agents. The fourth drug, necuparanib, another natural derivative, although structurally similar to roneparstat, is developed mainly as an antiangiogenic drug. It is noteworthy that this list lacks of small-molecule inhibitors, although various attempts have been made over time to select and develop a drug with suitable properties. To the best of our knowledge, to date no small molecule heparanase inhibitor has ever entered clinical trials. Similarly, none of the so-called biological drugs, such as vaccines, antibodies and nucleic acid-based therapies, has passed to clinical testing steps.

Probably, difficulties to obtain adequate amounts of highly pure and active enzyme with affordable costs 
Executive summary

\section{Background}

- Heparanase is a multifaceted protein endowed with both enzymatic and nonenzymatic activity, which represents a new powerful biological target for multiple therapeutic indications.

- Heparanase is the only known mammalian endo- $\beta$-D-glucuronidase capable to cleave the glycosaminoglycan heparan sulfate (HS) side chains of heparan sulfate proteoglycans (HSPGs), mainly located in the basement membrane, on the cell surface and the extracellular matrix (ECM), as well as in the nucleus of certain cells. This enzymatic activity ultimately results in the degradation and remodeling of ECM and in the release and activation of associated growth factors, lipoproteins, chemokines and enzymes.

Heparanase production \& activation, structure \& substrate specificity

- Heparanase was discovered more than 30 years ago and was cloned by different teams of researchers at the end of the last century.

- The primary structure of the protein is highly conserved among different animal species.

- In humans, a single copy HPSE gene, located on chromosome 4q21.3 and expressed as two mRNA species by alternative splicing, encodes heparanase.

- A complex biochemical process, including both intracellular and extracellular steps, allows maturation from the inactive pre-proheparanase form to the active noncovalent heterodimer, composed of an $\mathrm{N}$-terminal $8 \mathrm{kDa}$ and a C-terminal 50 kDa subunit.

- The recently solved crystal structure of human heparanase has confirmed the prediction of an $(\beta / \alpha)_{8}-$ TIM barrel fold (eight alternating $\beta$-strands and $\alpha$-helices) structure.

- Two heparin-binding domains (HBD-1 and HBD-2) are important for the interaction with HS chains, while several glycosylation residues contribute in regulating heparanase secretion.

- The minimum recognition backbone for heparanase substrates is a trisaccharide and the sulfation pattern seems to be more relevant than saccharide sequence for determining the efficiency of heparanase cleavage. The enzyme was shown to cleave mainly at the nonreducing side of highly sulfated HS domains.

\section{Physiological functions \& pharmacological applications}

- The relevance of heparanase as a new putative therapeutic target relies on the multitude of pathological conditions in which the enzyme plays a pivotal role.

- In physiological conditions, heparanase is expressed at high levels only in few tissues and in blood cells while in specific pathological conditions, such as tumors, it is upregulated and highly affects multiple biological processes, thus being also recognized as a negative prognostic marker.

- In most cases, heparanase function is strictly dependent on enzymatic degradation and remodeling of HS side chains of HSPGs, which ultimately affects many physiological and pathological processes, such as cell adhesion, proliferation, survival and differentiation, tumor development and metastasis, angiogenesis, inflammatory diseases and autoimmunity, diabetic nephropathy, aging and various rare diseases, including AA-amyloidosis, hereditary multiple exostoses, avascular necrosis of bones, fibrodysplasia ossificans progressiva and others.

- However, some of the multiple functions of heparanase are not mediated by its catalytic activity.

\section{In vitro assays of heparanase activity}

- A simple and reliable method suitable for quantitatively measuring heparanase activity is a prerequisite absolutely needed for screening for effective heparanase inhibitors.

- Various assays mainly based on the use of HS or simpler saccharide substrates for directly quantifying the rate of substrate cleavage, as a measure of heparanase enzymatic activity, have been developed and used in the last decades. Anyhow, in light of the growing interest in this target, an effort to choose common heparanase assay procedures would be of great value for selecting new potent and selective heparanase inhibitors on more directly comparable basis.

- Secondary cell-based or cell-free assays should also be used for assaying and confirming the activity of newly selected putative inhibitors.

\section{Strategies for heparanase activity inhibition}

- Various strategies for inhibiting heparanase activity, including vaccines, antisense oligonucleotides, antibodies, polysulfated saccharides (i.e., modified heparins and heparin derivatives) and even small-molecule inhibitors, have been developed and attempted in the last 20 years.

- All these approaches have been proven to be efficacious in many preclinical experimental models of different pathological disorders. 
Executive summary (cont.)

Inhibitors in clinical trials

- Despite several classes of inhibitors being investigated as anti-heparanase, to date only four drugs belonging to the class of polysaccharides, and obtained through semisynthetic methods or total synthesis, are currently trialed in:

- A Phase III study as an adjuvant treatment for patients with hepatitis virus related hepatocellular carcinoma after surgical resection; however, a recent interim analysis showed that the drug failed to meet the trial primary end point (PI-88 - muparfostat; developed by Progen Pharmaceuticals, licensed to Medigen Biotech, Corp.);

- A Phase I study in patients with solid tumors (PG545; developed by Progen Pharmaceuticals);

- A Phase I dose finding study assessing safety and tolerability in patients with advanced multiple myeloma (SST0001 - roneparstat; developed by Sigma-Tau Research Switzerland S.A., also thanks to a wide network of collaborations including Sigma-Tau IFR, G. Ronzoni Institute for Chemical and Biochemical Research and University of Parma).

- A Phase II study, with nab-paclitaxel and gemcitabine, in patients with pancreatic cancer (M-402 - necuparanib; developed by Momenta Pharmaceuticals).

\section{Future perspective}

- The biological role of heparanase has been widely demonstrated in numerous studies, and compounds able to specifically modulate the activity of this enzyme would offer a powerful pharmacological tool and/or a treatment option for many therapeutic indications.

- It is noteworthy that the current list of available drugs lacks of small-molecule inhibitors, although various attempts have been produced over time in order to select and develop a drug with these characteristics. To our knowledge, to date no small molecule has never entered clinical trials. Similarly, none of the so-called biological drugs, such as vaccines, antibodies and antisense therapies, has passed to clinical testing steps.

- The crystal structures of heparanase, from both the bacterial and human source, which have been very recently published, will probably assure a drastic improvement in this field, allowing designing efficient and selective heparanase inhibitors.

- Also the expected positive results of ongoing clinical trials, some of which in very advanced phase, might affect the fate of heparanase as a therapeutic target, at least in the oncology field.

have represented a major limitation for developing a drug targeted to heparanase. Another limitation, which is strictly associated with the previous one, was represented by the lack of heparanase crystallographic data that would favor inhibitor design. This last point is now overcome due to the recent reporting of crystal structures of both the bacterial and human enzyme by the groups of Bohlmann and $\mathrm{Wu}$, respectively [32,42]. It will be interesting to see in the coming years the impact of this new information on the research and development of drugs against heparanase.

Since heparanase is involved in a very wide range of molecular pathways, modulation of the expression or activity of this enzyme can be considered a viable therapeutic option, and potent and selective heparanase inhibitors might represent formidable tools for a real therapeutic challenge for those clinical indications in which heparanase inhibition may result pharmacologically useful. Furthermore, it must be underlined that animal models in which the heparanase gene has been knocked out are still able to survive without health problems [225]. Moreover, in order to block the nonenzymatic functions of heparanase, new strategies are needed to identify and characterize cell surface molecules that could function as receptors for the enzyme, and which could mediate its signaling activity.

\section{Future perspective}

A putative control of heparanase expression might be theoretically achieved by targeting its biosynthesis, from the pre-pro-heparanase stage up to the ultimate active form of the enzyme. Anyhow, according to the experimental evidences that have been accumulated so far, we would feel to rule out the hypothesis that a direct control of the heparanase biosynthesis process will be successfully performed in the next future. On the contrary, we think that effective modulation of the active heparanase form will be more likely realized in the next years. As already highlighted in the conclusions, the recently published crystallographic data could likely assure an impressive gain in the research and development of new inhibitors for this biological target. Moreover, the expected positive results of ongoing clinical trials, some of which in very advanced phase, might affect the fate of heparanase as a therapeutic target, at least in the oncology field.

According to the available data and due to the peculiar nature and biological role of this enzyme, it is likely that heparanase inhibitors, irrespective of their nature and source, that is, independently from being 
small molecules, polysaccharide derivatives or biological drugs, will be likely used in association with other drugs, rather than in single agent regimen, in future oncology therapeutic applications. Vice versa, heparanase inhibitors could be effective when used as monotherapy in therapeutic applications other than the oncological ones, such as in an anti-aging approach, given heparanase activation in human keratinocytes following acute and chronic UVB exposure (Supplementary Table 3) or for therapies targeted to cardiovascular pathologies, some rare diseases, etc. However, it is opinion of the authors that, by virtue of the multitude of experimental evidences on this target accumulated so far, in the next future, heparanase will surely have a relevant role and, for some aspects, a determinant role in very different fields spanning from prevention to diagnosis, or from monitoring to medical therapy. In this context, in addition to the strategies aimed at blocking the enzymatic activity of heparanase, identification of putative heparanase receptors mediating its signaling function, and better elucidation of the enzyme expression and function in the cell nucleus will certainly advance our under-

\section{References}

Papers of special note have been highlighted as:

- of interest; $\bullet \bullet$ of considerable interest

1 Nakajima M, Irimura T, Di Ferrante N, Nicolson GL. Metastatic melanoma cell heparanase. Characterization of heparan sulfate degradation fragments produced by B16 melanoma endoglucuronidase. J. Biol. Chem. 259(4), 2283-2290, (1984).

2 Nasser NJ, Nevo E. Heparanase patents: dim past and bright future. Recent Pat. Inflamm. Allergy Drug Discov. 7(2), 162-167 (2013).

3 Parish CR, Freeman C, Hulett MD. Heparanase: a key enzyme involved in cell invasion. Biochem. Biophys. Acta 1471(3), M99-M108 (2001).

$4 \quad$ Vlodavsky I, Friedmann Y. Molecular properties and involvement of heparanase in cancer metastasis and angiogenesis. J. Clin. Invest. 108(3), 341-347 (2001).

5 Vlodavsky I, Eldor A, Haimovitz-Friedman A et al. Expression of heparanase by platelets and circulating cells of the immune system: possible involvement in diapedesis and extravasation. Invasion Metast. 12(2), 112-127 (1992).

6 Chen LG, Sanderson RD. Heparanase regulates levels of syndecan-1in the nucleus. PLoS ONE 4(3), e4947 (2009).

7 Richardson TP, Trinkaus-Randall V, Nugent MA. Regulation of heparin sulfate proteoglycan nuclear localization by fibronectin. J. Cell Sci. 114(Pt 9), 1613-1623 (2001).

8 Fux L, Ilan N, Sanderson RD, Vlodavsky I. Heparanase: busy at the cell surface. Trends Biochem. Sci. 34(10), 511-519 (2009).

9 Ilan N, Elkin M, Vlodavsky I. Regulation, function, and clinical significance of heparanase in cancer metastasis and standing of heparanase role and significance in health and disease.

\section{Supplementary data}

To view the supplementary data that accompany this paper, please visit the journal website at: www.future-science.com/ doi/full/10.4155/fmc-2016-0012

\section{Financial \& competing interests disclosure}

This work was supported by Sigma-Tau Research Switzerland S.A. (Mendrisio, CH). The authors have no other relevant affiliations or financial involvement with any organization or entity with a financial interest in or financial conflict with the subject matter or materials discussed in the manuscript apart from those disclosed.

No writing assistance was utilized in the production of this manuscript.

\section{Open access}

This work is licensed under the Attribution-NonCommercialNoDerivatives 4.0 Unported License. To view a copy of this license, visit http://creativecommons.org/licenses/by-nc$\mathrm{nd} / 4.0 /$

angiogenesis. Int. J. Biochem. Cell Biol. 38(12), 2018-2039 (2006).

10 Reiland J, Kempf D, Roy M, Denkins Y, Marchetti D. FGF2 binding, signaling, and angiogenesis are modulated by heparanase in metastatic melanoma cells. Neoplasia 8(7), 596-560 (2006).

11 Reiland J, Sanderson RD, Waguespack M et al. Heparanase degrades syndecan-1 and perlecan heparan sulfate: functional implications for tumor cell invasion. J. Biol. Chem. 279(9), 8047-8055 (2004).

12 Mackenzie E, Tyson K, Stamps A et al. Cloning and expression profiling of $\mathrm{Hpa} 2$, a novel mammalian heparanase family member. Biochem. Biophys. Res. Commun. 276(3), 1170-1177 (2000).

13 Mahmood S, Beetz C, Tahir MM et al. First Hpse2 missense mutation in urofacial syndrome. Clin. Genet. 81(1), 88-92 (2012).

14 Levy-Adam F, Feld S, Cohen-Kaplan V et al. Heparanase 2 interacts with heparan sulfate with high affinity and inhibits heparanase activity. J. Biol. Chem. 285(36), 28010-28019 (2010).

15 Roberts NA, Woolf AS, Stuart HM et al. Heparanase 2 , mutated in urofacial syndrome, mediates peripheral neural development in Xenopus. Hum. Mol. Genet. 23(16), 4302-4314 (2014).

16 Merchant ZM, Kim YS, Rice KG, Linhardt R. Structure of heparin-derived tetrasaccharides. Biochem. J. 229(2), 369-377 (1985).

17 Kim BT, Kim WS, Kim YS, Linhardt RJ, Kim DH. Purification and characterization of a novel heparinase from Bacteroides stercoris HJ-15. J. Biochem. 128(2), 323-328 (2000). 
18 Davies GJ, Wilson KS, Henrissat B. Nomenclature for sugar-binding subsites in glycosyl hydrolases. Biochem. J. 321(Pt 2), 557-559 (1997).

19 Dong J, Kukula AK, Toyoshima M, Nakajima M. Genomic organization and chromosome localization of the newly identified human heparanase gene. Gene 253(2), 171-178, 2000.

20 Vlodavsky I, Friedmann Y, Elkin M et al. Mammalian heparanase: gene cloning, expression and function in tumor progression and metastasis. Nat. Med. 5(7), 793-802 (1999).

21 Hulett MD, Freeman C, Hamdorf BJ, Baker RT, Harris MJ, Parish CR. Cloning of mammalian heparanase, an important enzyme in tumor invasion and metastasis. Nat. Med. 5(7), 803-809 (1999).

22 Kussie PH, Hulmes JD, Ludwig DL et al. Cloning and functional expression of a human heparanase gene. Biochem. Biophys. Res. Commun. 261(1), 183-187 (1999).

23 Fairbanks MB, Mildner AM, Leone JW et al. Processing of the human heparanase precursor and evidence that the active enzyme is a heterodimer. J. Biol. Chem. 274(42), 29587-29590 (1999).

24 Toyoshima M, Nakajima M. Human heparanase. Purification, characterization, cloning, and expression. J. Biol. Chem. 274(34), 24153-24160 (1999).

25 Shteingauz A, Ilan N, Vlodavsky I. Processing of heparanase is mediated by syndecan-1 cytoplasmic domain and involves syntenin and \{Alpha\}-actinin. Cell Mol. Life Sci. 71(22), 4457-4470 (2014).

26 Fairbanks MB, Mildner AM, Leone JW et al. Processing of the human heparanase precursor and evidence that the active enzyme is a heterodimer. J. Biol. Chem. 274(42), 29587-29590 (1999).

27 Abboud-Jarrous G, Rangini-Guetta Z, Aingorn H et al. Site-directed mutagenesis, proteolytic cleavage, and activation of human proheparanase. J. Biol. Chem. 280(14), 13568-13575 (2005).

28 Vlodavsky I, Ilan N, Naggi A, Casu B. Heparanase: structure, biological functions, and inhibition by heparinderived mimetics of heparan sulfate. Curr. Pharm. Des. 13(20), 2057-2073 (2007).

29 Levy-Adam F, Miao HQ, Heinrikson RL, Vlodavsky I, Ilan N. Heterodimer formation is essential for heparanase enzymatic activity. Biochem. Biophys. Res. Commun. 308(4), 885-891 (2003)

30 Shafat I, Vlodavsky I, Ilan N. Characterization of mechanisms involved in secretion of active heparanase. J. Biol. Chem. 281(33), 23804-23811 (2006).

31 Levy-Adam F, Feld S, Suss-Toby E, Vlodavsky I, Ilan N. Heparanase facilitates cell adhesion and spreading by clustering of cell surface heparan sulfate proteoglycans. PLoS ONE 3(6), e2319 (2008).

32 Wu L, Viola CM, Brzozowski AM, Davies GJ. Structural characterization of human heparanase reveals insights into substrate recognition. Nat. Struct. Mol. Biol. 22(12), 1016-1022 (2015).

-. First paper on the $\mathrm{x}$-ray structure of human heparanase.
33 Barash U, Cohen-Kaplan V, Arvatz G et al. A novel human heparanase splice variant, $\mathrm{T} 5$, endowed with protumorigenic characteristics. FASEB J. 24(4), 1239-1248 (2010).

34 Nasser NJ, Avivi A, Shushy M, Vlodavsky I, Nevo E. Cloning, expression, and characterization of an alternatively spliced variant of human heparanase. Biochem. Biophys. Res. Commun. 354(1), 33-38 (2007).

35 Nardella C, Lahm A, Pallaoro M, Brunetti M, Vannini A, Steinkühler C. Mechanism of activation of human heparanase investigated by protein engineering. Biochemistry 43(7), 1862-1873 (2004).

36 Fux L, Feibish N, Cohen-Kaplan V et al. Structure-function approach identifies a $\mathrm{COOH}$-terminal domain that mediates heparanase signaling. Cancer Res. 69(5), 1758-1767 (2009).

37 Wilson JC, Laloo AE, Singh S, Ferro V. 1H NMR spectroscopic studies establish that heparanase is a retaining glycosidase. Biochem. Biophys. Res. Commun. 443(1), 185-188 (2014).

38 Hulett MD, Hornby JR, Ohms SJ et al. Identification of active-site residues of the pro-metastatic endoglycosidase heparanase. Biochemistry 39(51), 15659-15667 (2000).

39 Levy-Adam F, Abboud-Jarrous G, Guerrini M, Beccati D, Vlodavsky I, Ilan N. Identification and characterization of heparin/heparan sulfate binding domains of the endoglycosidase heparanase. J. Biol. Chem. 280 (21), 20457-20466 (2005).

40 Peterson SB, Liu J. Multi-faceted substrate specificity of heparanase. Matrix Biol. 32 (5), 223-227 (2013).

-. A nice review on substrate preference of heparanase and its potential pathophysiological relevance.

41 Mao Y, Huang Y, Buczek-Thomas JA et al. A liquid chromatography-mass spectrometry-based approach to characterize the substrate specificity of mammalian heparanase. J. Biol. Chem. 289(49), 34141-34151 (2014).

42 Bohlmann L, Tredwell GD, Yu X et al. Functional and structural characterization of a heparanase. Nat. Chem. Biol. 11(12), 955-957 (2015).

43 Zhou Z, Bates M, Madura JD. Structure modeling, ligand binding, and binding affinity calculation (LR-MM-PBSA) of human heparanase for inhibition and drug design. Proteins 65(3), 580-592 (2006).

44 Gandhi NS, Freeman C, Parish CR, Mancera RL. Computational analyses of the catalytic and heparin-binding sites and their interactions with glycosaminoglycans in glycoside hydrolase family 79 endo- $\beta$-D-glucuronidase (heparanase). Glycobiology 22(1), 35-55 (2012).

45 Fux L, Feibish N, Cohen-Kaplan V et al. Structure-function approach identifies a $\mathrm{COOH}$-terminal domain that mediates heparanase signaling. Cancer Res. 69(5), 1758-1767 (2009).

46 Sapay N, Cabannes E, Petitou M, Imberty A. Molecular model of human heparanase with proposed binding mode of a heparan sulfate oligosaccharide and catalytic amino acids. Biopolymers 97(1), 21-34 (2012).

47 Vinader V, Haji-Abdullahi MH, Patterson LH, Afarinkia K. Synthesis of a pseudo-disaccharide library and its application to the characterisation of the heparanase catalytic site. PLoS ONE 8(11), e82111 (2013) 
48 Pala D, Rivara S, Mor M et al. Kinetic analysis and molecular modelling of the inhibition mechanism of roneparstat (SST0001) on human heparanase. Glycobiology (2016) (Epub ahead of print). http://glycob.oxfordjournals.org/content/early/

- A paper on the mechanism of action of ronepastat.

49 Nasser NJ. Heparanase involvement in physiology and disease. Cell Mol. Life Sci. 65(11), 1706-1715 (2008).

50 Timar J, Lapis K, Dudas J, Sebestyen A, Kopper L, Kovalszky I. Proteoglycans and tumor progression: janusfaced molecules with contradictory functions in cancer. Semin. Cancer Biol. 12(3), 173-186 (2002).

51 Lindahl U, Kjellen L. Pathophysiokogy of heparin sulphate: many diseases, few drugs. J. Intern. Med. 273(6), 555-571 (2013).

52 Iozzo RV, Sanderson RD. Proteoglycans in cancer biology, tumour microenvironment and angiogenesis. J. Cell. Mol. Med. 15(5), 1013-1031 (2011).

53 Bishop JR, Schuksz M, Esko JD. Heparan sulphate proteoglycans fine-tune mammalian physiology. Nature 446(7139), 1030-1037 (2007).

54 Iozzo RV. Matrix proteoglycans: from molecular design to cellular function. Annu. Rev. Biochem. 67, 609-652 (1998).

55 Belting M. Heparan sulfate proteoglycan as a plasma membrane carrier. Trends Biochem. Sci. 28(3), 145-151 (2003).

56 Vlodavsky I, Friedmann Y. Molecular properties and involvement of heparanase in cancer metastasis and angiogenesis. J. Clin. Invest. 108(3), 341-347 (2001).

57 Gotte M. Syndecans in inflammation. FASEB J. 17(6), 575-591 (2003).

58 Vreys V, David G. Mammalian heparanase: what is the message? J. Cell. Mol. Med. 11(3), 427-452 (2007).

59 Li JP, Vlodavsky I. Heparin, heparan sulfate and heparanase in inflammatory reactions. Thromb. Haemost. 102(5), 823-828 (2009).

60 Pisano C, Vlodavsky I, Ilan N, Zunino F. The potential of heparanase as a therapeutic target in cancer. Biochem. Pharmacol. 89(1), 12-19 (2014).

- Nice overview on the role of heparanase in the cancer.

61 McKenzie EA. Heparanase: a target for drug discovery in cancer and inflammation. Br. J. Pharmacol. 151(1), 1-14 (2007).

62 Nadir Y, Brenner B. Heparanase multiple effects in cancer. Thromb. Res. 133(S2), S90-S94 (2014).

63 Hammond E, Khurana A, Shridhar V, Dredge K. The role of heparanase and sulfatases in the modification of heparan sulfate proteoglycans within the tumor microenvironment and opportunities for novel cancer therapeutics. Front. Oncol. 4, 195 (2014).

64 Masola V, Secchi MF, Gambaro G, Onisto M. Heparanase as a target in cancer therapy. Curr. Cancer Drug Targets 14(3), 286-293 (2014).

65 Sasisekharan R, Shriver Z, Venkataraman G, Narayanasami U. Roles of heparan-sulphate glycosaminoglycans in cancer. Nat. Rev. Cancer 2(7), 521-528 (2002).
66 Joyce JA, Freeman C, Meyer-Morse N, Parish CR, Hanahan D. A functional heparan sulfate mimetic implicates both heparanase and heparan sulfate in tumor angiogenesis and invasion in a mouse model of multistage cancer. Oncogene 24(25), 4037-4051 (2005).

67 Elkin M, Ilan N, Ishai-Michaeli R et al. Heparanase as mediator of angiogenesis: mode of action. FASEB J. 15(9), 1661-1663 (2001).

68 Nakajima M, Irimura T, Nicolson GL. Heparanase and tumor metastasis. J. Cell. Biochem. 36(2), 157-167 (1988).

69 Iozzo RV, San Antonio JD. Heparan sulfate proteoglycans: heavy hitters in the angiogenic arena. J. Clin. Invest. 108(3), 349-355 (2001).

70 Vlodavsky I, Miao H-Q, Medalion B, Danagher P, Ron D. Involvement of heparin sulfate and related molecules in sequestration and growth promoting activity of fibroblast growth factor. Cancer Metastasis Rev. 15(2), 177-186 (1996).

71 Purushothaman A, Uyama T, Kobayashi F et al. Heparanaseenhanced shedding of syndecan-1 by myeloma cells promotes endothelial invasion and angiogenesis. Blood 115(12), 2449-2457 (2010).

72 Goldshmidt O, Zcharia E, Cohen M et al. Heparanase mediates cell adhesion independent of its enzymatic activity. FASEB J. 17(9), 1015-1025 (2003).

73 He YQ, Sutcliffe EL, Bunting KL et al. The endoglycosidase heparanase enters the nucleus of $\mathrm{T}$ lymphocytes and modulates $\mathrm{H} 3$ methylation at actively transcribed genes via the interplay with key chromatin modifying enzymes. Transcription 3(3), 130-145 (2012).

74 Thompson CA, Purushothaman A, Ramani VC, Vlodavsky I, Sanderson RD. Heparanase regulates secretion, composition, and function of tumor cell-derived exosomes. J. Biol. Chem. 288(14), 10093-10099 (2013).

75 Cohen-Kaplan V, Doweck I, Naroditsky I, Vlodavsky I, Ilan $\mathrm{N}$. Heparanase augments epidermal growth factor receptor phosphorylation: correlation with head and neck tumor progression. Cancer Res. 68(24), 10077-10085 (2008).

76 Ramani VC, Yang Y, Ren Y, Nan L, Sanderson RD. Heparanase plays a dual role in driving hepatocyte growth factor (HGF) signaling by enhancing HGF expression and activity. J. Biol. Chem. 286(8), 6490-6499 (2011).

77 Purushothaman A, Babitz SK, Sanderson RD. Heparanase enhances the insulin receptor signaling pathway to activate ERK in multiple myeloma. J. Biol. Chem. 287(49), 41288-41296 (2012).

78 Cohen I, Pappo O, Elkin M et al. Heparanase promotes growth, angiogenesis and survival of primary breast tumors. Int. J. Cancer 118(7), 1609-1617 (2006).

79 Mahtouk K, Hose D, Raynaud P et al. Heparanase influences expression and shedding of syndecan- 1 , and its expression by the bone marrow environment is a bad prognostic factor in multiple myeloma. Blood 109(11), 4914-4923 (2007).

80 Lerner I, Baraz L, Pikarsky E et al. Function of heparanase in prostate tumorigenesis: potential for therapy. Clin. Cancer Res. 14(3), 668-676 (2008).

81 Brun R, Naroditsky I, Waterman M et al. Heparanase expression by Barrett's epithelium and during esophageal 
carcinoma progression. Mod. Pathol. 22(12), 1548-1554 (2009).

82 Jiang G, Zheng L, Pu J et al. Small RNAs targeting transcription start site induce heparanase silencing through interference with transcription initiation in human cancer cells. PLoS ONE 7(2), e31379 (2012).

83 Xiong Z, Lu MH, Fan YH et al. Downregulation of heparanase by RNA interference inhibits invasion and tumorigenesis of hepatocellular cancer cells in vitro and in vivo. Int. J. Oncol. 40(5), 1601-1609 (2012).

84 Barash U, Arvatz G, Farfara R et al. Clinical significance of heparanase splice variant (T5) in renal cell carcinoma: evaluation by a novel T5-specific monoclonal antibody. PLoS ONE 7(12), e51494 (2012).

85 Meirovitz A, Goldberg R, Binder A, Rubinstein AM, Hermano E, Elkin M. Heparanase enzyme in inflammation and inflammation-associated cancer. FEBS J. 280 (10), 2307-2319 (2013).

86 Brunn GJ, Bungum MK, Johnson GB, Platt JL. Conditional signaling by Toll-like receptor 4. FASEB J. 19(7), 872-874 (2005).

87 Parish CR. The role of heparan sulphate in inflammation. Nat. Rev. Immunol. 6(9), 633-643 (2006).

88 Taylor KR, Gallo RL. Glycosaminoglycans and their proteoglycans: host-associated molecular patterns for initiation and modulation of inflammation. FASEB J. 20(1), 9-22 (2006).

89 Bode L, Salvestrini C, Park PW et al. Heparan sulfate and syndecan-1 are essential in maintaining murine and human intestinal epithelial barrier function. J. Clin. Invest. 118(1), 229-238 (2008).

90 Akbarshahi H, Axelsson JB, Said K, Malmstrom A, Fischer H, Andersson R. TLR4 dependent heparan sulphate-induced pancreatic inflammatory response is IRF3-mediated. J. Transl. Med. 9, 219 (2011).

91 Axelsson J, Xu D, Kang BN et al. Inactivation of heparan sulfate 2-O-sulfotransferase accentuates neutrophil infiltration during acute inflammation in mice. Blood 120(8), 1742-1751 (2012).

92 Li RW, Freeman C, Yu D et al. Dramatic regulation of heparanase activity and angiogenesis gene expression in synovium from patients with rheumatoid arthritis. Arthritis Rheum. 58(6), 1590-1600 (2008).

93 El-Assal ON, Yamanoi A, Ono T, Kohno H, Nagasue $\mathrm{N}$. The clinicopathological significance of heparanase and basic fibroblast growth factor expressions in hepatocellular carcinoma. Clin. Cancer Res. 7(5), 1299-1305 (2001).

94 Koliopanos A, Friess H, Kleeff J et al. Heparanase expression in primary and metastatic pancreatic cancer. Cancer Res. 61(12), 4655-4659 (2001).

95 Waterman M, Ben-Izhak O, Eliakim R, Groisman G, Vlodavsky I, Ilan N. Heparanase upregulation by colonic epithelium in inflammatory bowel disease. Mod. Pathol. 20(1), 8-14 (2007)

96 Lerner I, Hermano E, Zcharia E et al. Heparanase powers a chronic inflammatory circuit that promotes colitis-associated tumorigenesis in mice. J. Clin. Invest. 121(5), 1709-1721 (2011).

97 Zhang X, Wang B, O'Callaghan P et al. Heparanase overexpression impairs inflammatory response and macrophage-mediated clearance of amyloid- $\beta$ in murine brain. Acta Neuropathol. 124(4), 465-478 (2012).

98 Trebicz-Geffen M, Robinson D, Evron $Z$ et al. The molecular and cellular basis of exostosis formation in hereditary multiple exostoses. Int. J. Exp. Pathol. 89(5), 321-331 (2008).

99 Huegel J, Enomoto-Iwamoto M, Sgariglia F, Koyama E, Pacifici M. Heparanase stimulates chondrogenesis and is up-regulated in human ectopic cartilage: a mechanism possibly involved in hereditary multiple exostoses. $\mathrm{Am}$. J. Pathol. 185(6), 1676-1685 (2015).

100 Oya-Angeler J, Gianakos AL, Villa JC, Ni A, Lane JM. Current concepts on osteonecrosis of the femoral head. World J. Orthop. 6(8), 590-601 (2015).

101 Mont MA, Jones LC, Hungerford DS. Nontraumatic osteonecrosis of the femoral head: ten years later. J. Bone Joint Surg. Am. 88(5), 1117-1132 (2006).

102 Peled E, Davis M, Axelman E, Norman D, Nadir Y. Heparanase role in the treatment of avascular necrosis of femur head. Thromb. Res. 131(1), 94-98 (2013).

103 Pignolo RJ, Shore EM, Kaplan FS. Fibrodysplasia ossificans progressiva: diagnosis, management, and therapeutic horizons. Pediatr. Endocrinol. Rev. 2, 437-448 (2013).

104 Jiao X, Billings PC, O'Connell MP, Kaplan FS, Shore EM, Glaser DL. Heparan sulfate proteoglycans (HSPGs) modulate BMP2 osteogenic bioactivity in $\mathrm{C} 2 \mathrm{C} 12$ cells. J. Biol. Chem. 282(2), 1080-1086 (2007).

105 O'Connell MP, Billings PC, Fiori JL et al. HSPG modulation of BMP signaling in fibrodysplasia ossificans progressiva cells. J. Cell Biochem. 102 (6), 1493-1503 (2007).

106 Westermark GT, Westermark P. Serum amyloid A and protein AA: molecular mechanisms of a transmissible amyloidosis. FEBS Lett. 583(16), 2685-2690 (2009).

107 Sipe JD, Cohen AS. Review: history of the amyloid fibril. J. Struct. Biol. 130(2-3), 88-98 (2000).

108 Wang B, Tan Y-X, Jia J et al. Accelerated resolution of AA amyloid in heparanase knockout mice is associated with matrix metalloproteases. PLoS ONE 7(7), e39899 (2012).

109 Bornstein J, Cohen Y, Zarfati D, Sela S, Ophir E. Involvement of heparanase in the pathogenesis of localized vulvodynia. Int. J. Gynecol. Pathol. 27(1), 136-141 (2008).

110 Riaz A, Ilan N, Vlodavsky I, Li J-P, Johansson S. Characterization of heparanase-induced phosphatidylinositol 3-kinase-AKT activation and its integrin dependence. J. Biol. Chem. 288(17), 12366-12375 (2013).

111 Harisi R, Jeney A. Extracellular matrix as target for antitumor therapy. OncoTargets Ther. 8, 1387-1398 (2015).

$112 \mathrm{Hu} \mathrm{X}$, Zhang L, Jin J et al. Heparanase released from mesenchymal stem cells activates integrin beta1/HIF-2alpha/ Flk-1 signaling and promotes endothelial cell migration and angiogenesis. Stem Cells 33(6), 1850-1862 (2015).

113 Munguti J, Sammy M. Mechanisms of tumor metastasis: anatomical mimicry? OA Anatomy 1(3), 23 (2013). 
114 Linhardt RJ, Galliher PM, Cooney CL. Polysaccharide lyases. Appl. Biochem. Biotech. 12(2), 135-176 (1986).

115 Vlodavsky I, Fuks Z, Bar-Ner M, Ariav Y, Schirrmacher V. Lymphoma cell-mediated degradation of sulfated proteoglycans in the subendothelial extracellular matrix: relationship to tumor cell metastasis. Cancer Res. 43(6), 2704-2711 (1983).

116 Edovitsky E, Elkin M, Zcharia E, Perez T, Vlodavsky I. Heparanase gene silencing, tumor invasiveness, angiogenesis, and metastasis. J. Natl Cancer Inst. 96(16), 1219-1230 (2004).

117 Freeman C, Parish CR. A rapid quantitative assay for the detection of mammalian heparanase activity. Biochem. J. 325(Pt 1), 229-237 (1997).

118 Fairweather JK, Hammond E, Johnstone KD, Ferro V. Synthesis and heparanase inhibitory activity of sulfated mannooligosaccharides related to the antiangiogenic agent PI-88. Bioorg. Med. Chem. 16(2), 699-709 (2008).

119 Bame KJ, Hassall A, Sanderson C, Venkatesan I, Sun C. Partial purification of heparanase activities in Chinese hamster ovary cells: evidence for multiple intracellular heparanases. Biochem. J. 336(Pt 1), 191-200 (1998).

120 Xu Y-J, Miao H-Q, Pan W et al. N- $(4-\{[4-(1 \mathrm{H}-$ Benzoimidazol-2-yl)-arylamino]-methyl\}-phenyl)benzamide derivatives as small molecule heparanase inhibitors. Bioorg. Med. Chem. Lett. 16(2), 404-408 (2006)

121 Toyoshima M, Nakajima M. Human heparanase. Purification, characterization, cloning, and expression. J. Biol. Chem. 274(34), 24153-24160 (1999).

122 Nardella C, Lahm A, Pallaoro M, Brunetti M, Vannini A, Steinkühler C. Mechanism of activation of human heparanase investigated by protein engineering. Biochemistry 43(7), 1862-1873 (2004).

123 Enomoto K, Okamoto H, Numata Y, Takemoto H. A simple and rapid assay for heparanase activity using homogeneous time-resolved fluorescence. J. Pharm. Biomed. Anal. 41(3), 912-917 (2006).

124 Behzad F, Brenchley PE. A multiwell format assay for heparanase. Anal. Biochem. 320 (2), 207-213 (2003).

125 Nakajima M, Welch DR, Irimura T, Nicolson GL. Basement membrane degradative enzymes as possible markers of tumor metastasis. Prog. Clin. Biol. Res. 212, 113-122 (1986).

126 Nakajima M, Irimura T, Nicolson GL. Tumor metastasisassociated heparanase (heparan sulfate endoglycosidase) activity in human melanoma cells. Cancer Lett. 31(3), 277-283 (1986).

127 Freeman C, Parish CR. Human platelet heparanase: purification, characterization and catalytic activity. Biochem J. 330 (Pt 3), 1341-1350 (1998).

128 Tsuchida S, Podyma-Inoue KA, Yanagishita M. Ultrafiltration-based assay for heparanase activity. Anal. Biochem. 331(1), 147-152 (2004).

129 Karoli T, Liu L, Fairweather JK et al. Synthesis, biological activity, and preliminary pharmacokinetic evaluation of analogues of a phosphosulfomannan angiogenesis inhibitor (PI-88). J. Med. Chem. 48(26), 8229-8236 (2005).
130 Xu X, Quiros RM, Maxhimer JB et al. Inverse correlation between heparan sulfate composition and heparanase-1 gene expression in thyroid papillary carcinomas: a potential role in tumor metastasis. Clin. Cancer Res. 9(16 Pt1), 5968-5979 (2003).

131 Huang KS, Holmgren J, Reik L et al. High-throughput methods for measuring heparanase activity and screening potential antimetastatic and anti-inflammatory agents. Anal. Biochem. 333(2), 389-398 (2004).

132 Enomoto K, Okamoto H, Numata Y, Takemoto H. A simple and rapid assay for heparanase activity using homogeneous time-resolved fluorescence. J. Pharm. Biomed. Anal. 41(3), 912-917 (2006).

133 Roy S, El Hadri A, Richard S et al. Synthesis and biological evaluation of a unique heparin mimetic hexasaccharide for structure-activity relationship studies. J. Med. Chem. 57(11), 4511-4520 (2014).

134 Achour O, Poupard N, Bridiau N et al. Anti-heparanase activity of ultra-low-molecular-weight heparin produced by physicochemical depolymerization. Carbohydr. Polym. 135, 316-323 (2016).

135 Courtney SM, Hay PA, Buck RT et al. 2,3-Dihydro-1,3dioxo- $1 \mathrm{H}$-isoindole-5-carboxylic acid derivatives: a novel class of small molecule heparanase inhibitors. Bioorg. Med. Chem. Lett. 14(12), 3269-3273 (2004).

136 Hammond E, Li CP, Ferro V. Development of a colorimetric assay for heparanase activity suitable for kinetic analysis and inhibitor screening. Anal. Biochem. 396(1), 112-116 (2010).

137 Schiemann S, Lühn S, Alban S. Development of both colorimetric and fluorescence heparinase activity assays using fondaparinux as substrate. Anal. Biochem. 427(1), 82-89 (2012).

138 Mucciolo Melo C, Tersariol ILS, Nader HB, Pinhal MA, Lima MA. Development of new methods for determining the heparanase enzymatic activity. Carbohydr. Res. 412, 66-70 (2015).

139 Gandhi NS, Freeman C, Parish CR, Mancera RL. Computational analyses of the catalytic and heparinbinding sites and their interactions with glycosaminoglycans in glycoside hydrolase family 79 endo- $\beta$-D-glucuronidase (heparanase). Glycobiology 22(1), 35-55 (2012).

140 Bisio A, Mantegazza A, Urso E et al. High-performance liquid chromatographic/mass spectrometric studies on the susceptibility of heparin species to cleavage by heparanase. Semin. Thromb. Hemost. 33(5), 488-495 (2007).

141 Chen J, Zhou Y, Chen C, Xu W, Yu B. Synthesis of a tetrasaccharide substrate of heparanase. Carbohydr. Res. 343(17), 2853-2862 (2008).

142 Pearson AG, Kiefel MJ, Ferro V, von Itzstein M. Synthesis of simple heparanase substrates. Org. Biomol. Chem. 9(12), 4614-4625 (2011).

143 Takeda N, Ikeda-Matsumi R, Ebara-Nagahara K et al. Synthesis of heparan sulfate tetrasaccharide as a substrate for human heparanase. Carbohydr. Res. 353, 13-21 (2012).

144 McKenzie E, Young K, Hircock M et al. Biochemical characterization of the active heterodimer form of human 
heparanase (Hpa1) protein expressed in insect cells. Biochem. J. 373 (Pt 2), 423-435 (2003).

145 Marchetti D, Reiland J, Erwin B, Roy M. Inhibition of heparanase activity and heparanase-induced angiogenesis by suramin analogues. Int. J. Cancer 104(2), 167-174 (2003).

146 Nadanaka S, Purunomo E, Takeda N, Tamura J, Kitagawa $\mathrm{H}$. Heparan sulfate containing unsubstituted glucosamine residues. J. Biol. Chem. 289 (22), 15231-15243 (2014).

147 Ishida K, Hirai G, Murakami K et al. Structure-based design of a selective heparanase inhibitor as an antimetastatic agent. Mol. Cancer Ther. 3(9), 1069-1077 (2004).

148 Naggi A, Casu B, Perez M et al. Modulation of the heparanase-inhibiting activity of heparin through selective desulfation, graded $N$-acetylation, and glycol splitting. J. Biol. Chem. 280 (13), 12103-12113 (2005).

- Reports the discovery of the heparanase inhibitor roneparstat (SST0001) currently under clinical investigation.

149 Cochran S, Li C, Fairweather JK, Kett WC, Coombe DR, Ferro V. Probing the interactions of phosphosulfomannans with angiogenic growth factors by surface plasmon resonance. J. Med. Chem. 46(21), 4601-4608 (2003).

150 Zhou H, Roy S, Cochran E et al. M402, a novel heparan sulfate mimetic, targets multiple pathways implicated in tumor progression and metastasis. PLoS ONE 6(6) e21106 (2011).

151 Ferro V, Hammond E, Fairweather JK. The development of inhibitors of heparanase, a key enzyme involved in tumour metastasis, angiogenesis and inflammation. Mini Rev. Med. Chem. 4(6), 693-702 (2004).

152 Miao HQ, Liu H, Navarro E, Kussie P, Zhu Z. Development of heparanase inhibitors for anti-cancer therapy. Curr. Med. Chem. 13(18), 2101-2111 (2006).

153 Vlodavsky I, Ilan N, Naggi A, Casu B. Heparanase: structure, biological functions, and inhibition by heparinderived mimetics of heparan sulfate. Curr. Pharm. Des. 13(20), 2057-2073 (2007).

154 Parish CR, Coombe DR, Jakobsen KB, Bennett FA, Underwood PA. Evidence that sulphated polysaccharides inhibit tumour metastasis by blocking tumour-cell-derived heparanases. Int. J. Cancer 40 (4), 511-518 (1987).

155 Miao HQ, Elkin M, Aingorn E, Ishai-Michaeli R, Stein CA, Vlodavsky I. Inhibition of heparanase activity and tumor metastasis by laminarin sulfate and synthetic phosphorothioate oligodeoxynucleotides. Int. J. Cancer 83(3), 424-431 (1999).

156 Saiki I, Murata J, Nakajima M, Tokura S, Azuma I. Saiki I, Murata J, Nakajima M, Tokura S, Azuma I. Cancer Res. 50(12), 3631-3637 (1990).

157 Parish CR, Freeman C, Brown KJ, Francis DJ, Cowden WB. Identification of sulfated oligosaccharide-based inhibitors of tumor growth and metastasis using novel in vitro assays for angiogenesis and heparanase activity. Cancer Res. 59(14), 3433-3441 (1999).

158 Lauver DA, Lucchesi BR. Sulodexide: a renewed interest in this glycosaminoglycan. Cardiovasc. Drug Rev. 24(3-4), 214-226 (2006).
159 Masola V, Onisto M, Zaza G, Lupo A, Gambaro G. A new mechanism of action of sulodexide in diabetic nephropathy: inhibits heparanase-1 and prevents FGF-2-induced renal epithelial mesenchymal transition. J. Transl. Med. 10, 213 (2012)

160 Freeman C, Liu L, Banwell MG et al. Use of sulfated linked cyclitols as heparan sulfate mimetics to probe the heparin/ heparan sulfate binding specificity of proteins. J. Biol. Chem. 280 (10), 8842-8849 (2005).

161 He X, Brenchley PE, Jayson GC, Hampson L, Davies J, Hampson IN. Hypoxia increases heparanase-dependent tumor cell invasion, which can be inhibited by antiheparanase antibodies. Cancer Res. 64(11), 3928-3933 (2004).

162 Levidiotis V, Freeman C, Tikellis C, Cooper ME, Power DA. Heparanase is involved in the pathogenesis of proteinuria as a result of glomerulonephritis. J. Am. Soc. Nephrol. 15(1), 68-78 (2004).

163 Levidiotis V, Freeman C, Tikellis C, Cooper ME, Power DA. Heparanase inhibition reduces proteinuria in a model of accelerated anti-glomerular basement membrane antibody disease. Nephrology (Carlton) 10(2), 167-173 (2005).

164 Myler HA, Lipke EA, Rice EE, West JL. Novel heparanaseinhibiting antibody reduces neointima formation. J. Biochem. 139(3), 339-345 (2006).

165 Yang JM, Wang HJ, Du L et al. Screening and identification of novel B cell epitopes in human heparanase and their anti-invasion property for hepatocellular carcinoma. Cancer Immunol. Immunother. 58(9), 1387-1396 (2009).

166 Barash U, Arvatz G, Farfara R et al. Clinical significance of heparanase splice variant $(\mathrm{t} 5)$ in renal cell carcinoma: evaluation by a novel $\mathrm{t} 5$-specific monoclonal antibody. PLoS ONE 7(12), e51494 (2012).

167 Weissmann M, Arvatz G, Horowitz N et al. Heparanaseneutralizing antibodies attenuate lymphoma tumor growth and metastasis. Proc. Natl Acad. Sci. USA 113(3), 704-709 (2016).

168 Fu J, Zhao B, Dong Z et al. Heparanase DNA vaccine delivered by electroporation induces humoral immunity and cytoimmunity in animal models. Vaccine 30 (12), 2187-2196 (2012).

- A complete and exhaustive paper on the attempt to use anti-heparanase vaccines.

169 Tang XD, Wang GZ, Guo J et al. Multiple antigenic peptides based on $\mathrm{H}-2 \mathrm{~K}(\mathrm{~b})$-restricted CTL epitopes from murine heparanase induce a potent antitumor immune response in vivo. Mol. Cancer Ther. 11(5), 1183-1192 (2012).

170 Wang GZ, Tang XD, Lü MH et al. Multiple antigenic peptides of human heparanase elicit a much more potent immune response against tumors. Cancer Prev. Res. (Phila.) 4(8), 1285-1295 (2011).

171 Zhang J, Yang JM, Wang HJ, Ru GQ, Fan DM. Synthesized multiple antigenic polypeptide vaccine based on B-cell epitopes of human heparanase could elicit a potent antimetastatic effect on human hepatocellular carcinoma in vivo. PLoS ONE 8(1), e52940 (2013).

172 Zhang J, Yang J, Cai Y, Jin N, Wang H, Yu T. Multiple antigenic polypeptide composed of heparanase B-cell 
epitopes shrinks human hepatocellular carcinoma in mice. Oncol. Rep. 33(3), 1248-1256 (2015).

173 Tang XD, Guo SL, Wang GZ et al. In vitro and ex vivo evaluation of a multi-epitope heparinase vaccine for various malignancies. Cancer Sci. 105(1), 9-17 (2014).

174 Mitsiades CS, Rouleau C, Echart C et al. Preclinical studies in support of defibrotide for the treatment of multiple myeloma and other neoplasias. Clin. Cancer Res. 15(4), 1210-1221 (2009).

175 Huining L, Yi Z, Dihong T et al. Inhibition of choriocarcinoma by Fe3O4-dextran-anti- $\beta$-human chorionic gonadotropin nanoparticles containing antisense oligodeoxynucleotide of heparanase. Int. J. Nanomedicine 8(1), 4371-4378 (2013).

176 Simmons SC, McKenzie EA, Harris LK et al. Development of novel single-stranded nucleic acid aptamers against the pro-angiogenic and metastatic enzyme heparanase (HPSE1). PLoS ONE 7(6), e37938 (2012).

177 Simmons SC, Jämsä H, Silva D et al. Anti-heparanase aptamers as potential diagnostic and therapeutic agents for oral cancer. PLoS ONE 9(10), e96846 (2014).

178 Edovitsky E, Lerner I, Zcharia E, Peretz T, Vlodavsky I, Elkin M. Role of endothelial heparanase in delayed-type hypersensitivity. Blood 107(9), 3609-3616 (2006).

179 Edovitsky E, Elkin M, Zcharia E, Peretz T, Vlodavsky I. Heparanase gene silencing, tumor invasiveness, angiogenesis, and metastasis. J. Natl Cancer. Inst. 96(16), 1219-1230 (2004).

180 Dong W, Zhao H, Zhang C et al. Gene silencing of heparanase results in suppression of invasion and migration of hepatoma cells. World J. Surg. Oncol. 12, 85 (2014).

181 Xiong Z, Lü MH, Fan YH et al. Downregulation of heparanase by RNA interference inhibits invasion and tumorigenesis of hepatocellular cancer cells in vitro and in vivo. Int. J. Oncol. 40 (5), 1601-1609 (2012).

182 Jiang G, Zheng L, Pu J et al. Small RNAs targeting transcription start site induce heparanase silencing through interference with transcription initiation in human cancer cells. PLoS ONE 7(2), e31379 (2012).

183 Liu M, Zhang Y, Liao Y et al. Evaluation of the antitumor efficacy of RNAi-mediated inhibition of CDC20 and heparanase in an orthotopic liver tumor model. Cancer Biother. Radiopharm. 30(6), 233-239 (2015).

184 Liu X, Fang H, Chen $\mathrm{H}$ et al. An artificial miRNA against HPSE suppresses melanoma invasion properties, correlating with a down-regulation of chemokines and MAPK phosphorylation. PLoS ONE 7(6), e38659 (2012).

185 Liu XY, Tang QS, Chen HC, Jiang XL, Fang H. Lentiviral miR30-based RNA interference against heparanase suppresses melanoma metastasis with lower liver and lung toxicity. Int. J. Biol. Sci. 9(6), 564-577 (2013).

186 Shiozawa H, Takahashi H, Takatsu T et al. Trachyspic acid, a new metabolite produced by Talaromyces trachyspermus, that inhibits tumor cell heparanase: taxonomy of the producing strain, fermentation, isolation, structural elucidation, and biological activity. J. Antibiot. 48(5), 357-362 (1995).

187 Jpn. Kokai Tokkyo Koho JP 05086085A (1993).
188 Shiozawa H, Takahashi M, Takatsu T et al. Trachyspic acid, a new metabolite produced by Talaromyces trachyspermus, that inhibits tumor cell heparanase: taxonomy of the producing strain, fermentation, isolation, structural elucidation, and biological activity. J. Antibiot. (Tokyo) 48(5), 357-362 (1995).

189 Zammit S, Ferro V, Hammond E, Rizzacasa MA. Enantiospecific synthesis of the heparanase inhibitor $(+)$-trachyspic acid and stereoisomers from a common precursor. Org. Biomol. Chem. 5(17), 2826-2834 (2007).

190 Nakajima M, DeChavigny A, Johnson CE, Hamada J, Stein CA, Nicolson GL. Suramin. A potent inhibitor of melanoma heparanase and invasion. J. Biol. Chem. 266(15), 9661-9666 (1991).

191 Ishida K, Hirai G, Murakami K et al. Structure-based design of a selective heparanase inhibitor as an antimetastatic agent. Mol. Cancer Ther. 3(9), 1069-1077 (2004).

192 Insight Strategy and Marketing Ltd: WO02060373 (2002).

193 Insight Strategy and Marketing Ltd: WO02060375 (2002).

194 Insight Strategy and Marketing Ltd: WO02060867 (2002).

195 Marchetti D, Reiland J, Erwin B, Roy M. Inhibition of heparanase activity and heparanase-induced angiogenesis by suramin analogues. Int. J. Cancer 104(2), 167-174 (2003).

$196 \mathrm{Li} \mathrm{H}, \mathrm{Li} \mathrm{H}, \mathrm{Qu} \mathrm{H}$ et al. Suramin inhibits cell proliferation in ovarian and cervical cancer by downregulating heparanase expression. Cancer Cell. Int. 15, 52 (2015).

197 Roggo BE, Petersen F, Delmendo R, Jenny HB, Peter HH, Roesel J. 3-alkanoyl-5-hydroxymethyl tetronic acid omologues and resistomycin: new inhibitors of HIV-1 protease I. Fermentation, isolation and biological activity. J. Antibiot. 47(2), 136-142 (1994).

198 Courtney SM, Hay PA, Buck RT et al. Furanyl-1,3-thiazol2-yl and benzoxazol-5-yl acetic acid derivatives: novel classes of heparanase inhibitor. Bioorg. Med. Chem. Lett. 15(9), 2295-2299 (2005).

199 Pan W, Miao HQ, Xu YJ et al. 1-[4-(1H-Benzoimidazol2-yl)-phenyl]-3-[4-(1H-benzoimidazol-2-yl)-phenyl]-urea derivatives as small molecule heparanase inhibitors. Bioorg. Med. Chem. Lett. 16(2), 409-412 (2006).

200 Gozalbes R, Mosulén S, Ortí L et al. Hit identification of novel heparanase inhibitors by structure- and ligand-based approaches. Bioorg. Med. Chem. 21(7), 1944-1951 (2013).

201 Basappa, , Murugan S, Kavitha CV et al. A small oxazine compound as an anti-tumor agent: a novel pyranoside mimetic that binds to VEGF, HB-EGF, and TNF- $\alpha$. Cancer Lett. 297(2), 231-243 (2010).

202 Kawase Y, Takahashi M, Takatsu T, Arai M, Nakajima M, Tanzawa K. A-72363 A-1, A-2, and C, novel heparanase inhibitors from Streptomyces nobilis SANK 60192, II. Biological activities. J. Antibiot. (Tokyo) 49(1), 61-64 (1996).

203 Nishimura Y, Shitara E, Adachi $\mathrm{H}$ et al. Flexible synthesis and biological activity of uronic acid-type gemdiamine 1-N-iminosugars: a new family of glycosidase inhibitors. J. Org. Chem. 65(1), 2-11 (2000).

204 Dredge K, Hammond E, Davis K et al. The PG500 series: novel heparan sulfate mimetics as potent angiogenesis and heparanase inhibitors for cancer therapy. Invest. New Drugs 28(3), 276-283 (2010). 
205 Hammond E, Handley P, Dredge K, Bytheway I. Mechanisms of heparanase inhibition by the heparan sulfate mimetic PG545 and three structural analogues. FEBS Open Biol. 3, 346-351 (2013).

206 Page C. Heparin and related drugs: beyond anticoagulant activity. ISRN Pharmacol. 2013, 910743 (2013).

207 Lapierre F, Holme K, Lam L et al. Chemical modifications of heparin that diminish its anticoagulant but preserve its heparanase-inhibitory, angiostatic, anti-tumor and antimetastatic properties. Glycobiology 6(3), 355-366 (1996).

208 Casu B, Guerrini M, Naggi A et al. Short heparin sequences spaced by glycol-split uronate residues are antagonists of fibroblast growth factor 2 and angiogenesis inhibitors. Biochemistry 41(33), 10519-10528 (2002).

209 Kudchadkar R, Gonzalez R, Lewis KD. PI-88: a novel inhibitor of angiogenesis. Expert Opin. Investig. Drugs 17(11), 1769-1776 (2008).

- An interesting paper on the discovery of the drug candidate PI-88 currently under clinical investigation.

210 Medigen Press Release July 29th, 2014. www.medigen.com.tw/en/further-explanation/

211 Brennan TV, Lin L, Brandstadter JD et al. Heparan sulfate mimetic PG545-mediated antilymphoma effects require TLR9-dependent NK cell activation. J. Clin. Invest. 126(1), 207-219 (2016)

212 Ferro V, Liu L, Johnstone KD et al. Discovery of PG545: a highly potent and simultaneous inhibitor of angiogenesis, tumor growth, and metastasis. J. Med. Chem. 55(8), 3804-3813 (2012)

213 Winterhoff B, Freyer L, Hammond E et al. PG545 enhances anti-cancer activity of chemotherapy in ovarian models and increases surrogate biomarkers such as VEGF in preclinical and clinical plasma samples. Eur. J. Cancer 51(7), 879-892 (2015).

214 Cassinelli G, Lanzi C, Tortoreto M et al. Antitumor efficacy of the heparanase inhibitor SST0001 alone and in combination with antiangiogenic agents in the treatment of human pediatric sarcoma models. Biochem. Pharmacol. 85(10), 1424-1432 (2013).

215 Shafat I, Ben-Arush MW, Issakov J et al. Pre-clinical and clinical significance of heparanase in Ewing's sarcoma. J. Cell Mol. Med. 15(9), 1857-1864 (2011).

216 Zhang L, Ngo JA, Wetzel MD, Marchetti D. Heparanase mediates a novel mechanism in lapatinib-resistant brain metastatic breast cancer. Neoplasia 17(1), 101-113 (2015).

217 Meirovitz A, Hermano E, Lerner I et al. Role of heparanase in radiation-enhanced invasiveness of pancreatic carcinoma. Cancer Res. 71(7), 2772-2780 (2011).

218 Ritchie JP, Ramani VC, Ren Y et al. SST0001, a chemically modified heparin, inhibits myeloma growth and angiogenesis via disruption of the heparanase/syndecan-1 axis. Clin. Cancer Res. 17(6), 1382-1393 (2011).

219 Ramani VC, Zhan F, He J et al. Targeting heparanase overcomes chemoresistance and diminishes relapse in myeloma. Oncotarget 7(2), 1598-1607 (2016).

220 Galli M, Magen H, Einsele H et al. Roneparstat (SST0001), an innovative heparanase (HPSE) inhibitor for multiple myeloma (MM) therapy: first in man study. Blood Abstracts: 57th Annual Meeting Abstracts 126(23), 3246 (2015).

221 Momenta Pharmeuticals Press Releases Nov 13th 2015 http://ir.momentapharma.com/releasedetail.cfm

222 Shteingauz A, Boyango I, Naroditsky I. Heparanase enhances tumor growth and chemoresistance by promoting autophagy. Cancer Res. 75(18), 3946-3957 (2015).

$223 \mathrm{Wu} \mathrm{X}, \mathrm{Yu}$ J, Gao G et al. Salivary heparanase level is a potential biomarker to diagnose and prognose the malignant salivary gland tumor. PLoS ONE 10(11), e0143009 (2015).

224 Leiser Y, Shilo D, Abu El Naaj I, Rachmiel A. Heparanase, a potential marker for premalignant oral cavity cancer. In vivo 28(5), 769-777 (2014).

225 Zcharia E, Jia J, Zhang X et al. Newly generated heparanase knock-out mice unravel co-regulation of heparanase and matrix metalloproteinases. PLoS ONE 4(4), e5181 (2009). 